Review Article

\title{
A New Hope in Immunotherapy for Malignant Gliomas: Adoptive T Cell Transfer Therapy
}

\author{
Dong-Sup Chung, ${ }^{1}$ Hye-Jin Shin, ${ }^{2}$ and Yong-Kil Hong ${ }^{2}$ \\ ${ }^{1}$ Department of Neurosurgery, Incheon St. Mary's Hospital, The Catholic University of Korea College of Medicine, \\ Dongsuro 56, Bupyeong-gu, Incheon 403-720, Republic of Korea \\ ${ }^{2}$ Department of Neurosurgery, Seoul St. Mary's Hospital, The Catholic University of Korea College of Medicine, \\ Banpodaero 222, Seocho-gu, Seoul 137-701, Republic of Korea
}

Correspondence should be addressed to Yong-Kil Hong; hongyk@catholic.ac.kr

Received 14 February 2014; Revised 2 May 2014; Accepted 18 May 2014; Published 9 June 2014

Academic Editor: Bin Zhang

Copyright (C) 2014 Dong-Sup Chung et al. This is an open access article distributed under the Creative Commons Attribution License, which permits unrestricted use, distribution, and reproduction in any medium, provided the original work is properly cited.

\begin{abstract}
Immunotherapy emerged as a promising therapeutic approach to highly incurable malignant gliomas due to tumor-specific cytotoxicity, minimal side effect, and a durable antitumor effect by memory T cells. But, antitumor activities of endogenously activated $\mathrm{T}$ cells induced by immunotherapy such as vaccination are not sufficient to control tumors because tumor-specific antigens may be self-antigens and tumors have immune evasion mechanisms to avoid immune surveillance system of host. Although recent clinical results from vaccine strategy for malignant gliomas are encouraging, these trials have some limitations, particularly their failure to expand tumor antigen-specific $\mathrm{T}$ cells reproducibly and effectively. An alternative strategy to overcome these limitations is adoptive $\mathrm{T}$ cell transfer therapy, in which tumor-specific $\mathrm{T}$ cells are expanded ex vivo rapidly and then transferred to patients. Moreover, enhanced biologic functions of $\mathrm{T}$ cells generated by genetic engineering and modified immunosuppressive microenvironment of host by homeostatic $\mathrm{T}$ cell expansion and/or elimination of immunosuppressive cells and molecules can induce more potent antitumor $\mathrm{T}$ cell responses and make this strategy hold promise in promoting a patient response for malignant glioma treatment. Here we will review the past and current progresses and discuss a new hope in adoptive T cell therapy for malignant gliomas.
\end{abstract}

\section{Introduction}

The prognosis of malignant glioma patients is grim despite the advanced multimodality therapies including surgery, radiotherapy, and chemotherapy. Immunotherapy emerged as a potential therapeutic approach to the highly incurable malignant gliomas, for which, however, either encouraging results or disappointing limitations were revealed as an alternative strategy $[1,2]$.

Tumor-specific $\mathrm{CD}^{+}$cytotoxic $\mathrm{T}$ lymphocytes (CTLs) are generated by repetitive stimulation of peripheral blood mononuclear cells (PBMCs) with tumor-associated antigen (TAA) expressing antigen-presenting cells (APC) such as dendritic cells (DCs) and certain cytokines including interleukin- (IL-) 2, IL-7, IL-12, IL-15, and IL-21 [3, 4]. These cells can be expanded rapidly ex vivo to use them for adoptive cell therapy (ACT). Antigen sources for this procedure include major histocompatibility complex- (MHC-) restricted peptides, recombinant proteins, tumor lysates, and genetically introduced tumor antigen genes. $\mathrm{CD}^{+} \mathrm{T}$ cells may also exert antitumor effector functions mainly through the secretion of interferon- (IFN-) $\gamma$ [5].

Theoretically, tumor-specific CTLs can move to TAAoverexpressed tumor cells specifically and kill them without adverse effects on normal cells. But, immune system may recognize these TAAs as self-antigens, leading to decreased T cell response to tumor cells because TAAs are also somewhat expressed in normal tissues [6,7]. T cells with high affinity to self-antigen may be physiologically removed through the mechanisms of immune tolerance, so the endogenously activated tumor-specific $\mathrm{T}$ cells have low affinity to self-antigen, inducing limited $\mathrm{T}$ cell response [8]. Furthermore, tumors 


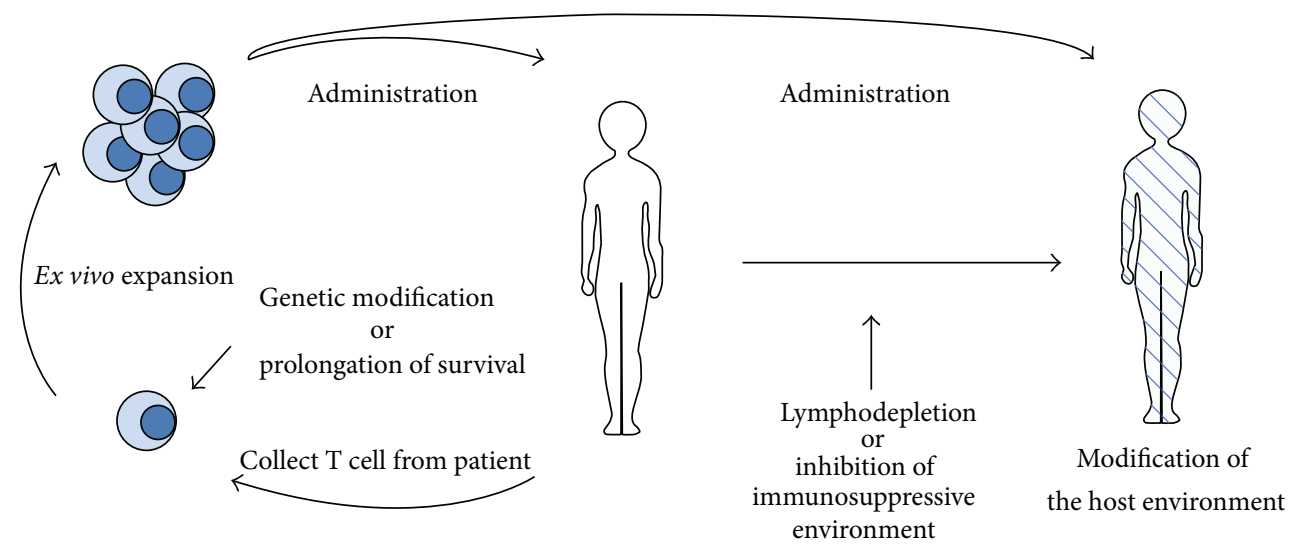

(a)

(b)

FIGURE 1: Adoptive T cell transfer therapy. (a) Enhancement of tumor-specific T cell function. (b) Modification of the host environment.

have evolved numerous mechanisms to evade both innate and adaptive immunity. These include modulation of $\mathrm{MHC}$ antigens and costimulatory molecules, expression of Fas ligand and other apoptotic molecules on the cell surface, production of inhibitory molecules such as transforming growth factor- (TGF-) $\beta$ and IL-10, constitutive expression of the tryptophan-depleting enzyme, indoleamine 2,3-dioxygenase (IDO), and recruitment of regulatory T cells (Tregs) [9].

Results from recent immunotherapeutic clinical trials with tumor cell or DC vaccines for malignant glioma patients were encouraging [10-13]. These trials, however, have shown some limitations, particularly their failure to expand tumor antigen-specific $\mathrm{T}$ cells reproducibly and effectively, suggesting that endogenous activation of $\mathrm{T}$ cells is insufficient to control tumors. A strategy to overcome these limitations is adoptive $\mathrm{T}$ cell transfer, in which tumor-specific $\mathrm{T}$ cells are expanded ex vivo rapidly and then transferred to patients. Moreover, a recent advance in delivering therapeutic genes into somatic cells has been applicable to $\mathrm{T}$ cell therapy for tumors. T cells used in ACT can be modified to increase their specificity and survival for the tumor or to make them resistant to immune evasion mechanisms [14-25] (Figure 1). $\mathrm{T}$ cell response for malignant gliomas also can be improved by combination with other therapeutic modalities [26, 27].

Here we will review past experiences and discuss current promising strategies of adoptive $\mathrm{T}$ cell therapy for malignant gliomas.

\section{Immune Environment of Malignant Glioma}

The brain has long been considered to be immunologically privileged due to immediate inability to reject intracranial xenograft in early report [28], physical isolation from the systemic immune system by the blood-brain-barrier (BBB), and lack of connections to the lymphatic system. Subsequent studies, however, have described the efficient rejection of intracranial xenografts and allografts in immunocompetent hosts abundantly [29], capability of activated T cells to cross the $\mathrm{BBB}[30,31]$, and the drainage of cerebrospinal fluid
TABLE 1: Glioma-associated antigens.

\begin{tabular}{ll}
\hline Classification & Antigens [references] \\
\hline Mutated antigens & EGFRvIII [35] \\
Cancer-testis antigens & MAGE [36], GAGE [37], and SOX6 \\
Tissue-specific antigens & Gp100 [39], TRP-2 [40] \\
& IL-13R $\alpha 2$ [41], EphA2 [42], EphB6 \\
Others & [43], HER-2[39], AIM-2 [44], SOX11 \\
& [45], surviving [46], telomerase [47], \\
& Mart-1 [48], and KIF3C [49] \\
\hline
\end{tabular}

into systemic lymphatics [32]. In addition, no specific CNSassociated antigens have been known that are systematically immunogenic but evade immune surveillance within the brain unlike testes, other immunologically privileged site [33]. Microglia, resident APCs in the brain, play a crucial role in the CNS immune response [34]. Collectively, these results clearly indicate that the brain is not an immunologically privileged site, but may be an organ that has immunologically particular environment although not fully understood.

A critical step for an efficient stimulation of adaptive immune response even in the brain is the identification of suitable tumor-specific or tumor-associated antigens that can be recognized and eliminated by the immune system. Malignant glioma is known to be genetically heterogenous with a variety of antigen profile [48], so glioma cells are inefficient for antigen processing. Difficulty in identification of ideal tumor antigens for immunotherapy as well as the abovementioned immune evasion mechanisms and the presence of immune inhibitory cells may render malignant glioma resistant to $\mathrm{T}$ cell responses. The source of antigen used in initial immunotherapeutic approaches to the malignant glioma was tumor lysates derived from autologous irradiated glioma cells [50]. Numerous glioma-associated antigens have been identified over the past decades and the antigens most suitable for activating the host-specific T cell response are still under investigation (Table 1). The glioma-specific antigens used in recent preclinical or clinical studies showing potent 
TABLE 2: Comparison of the effector cells used in adoptive $\mathrm{T}$ cell therapy for malignant glioma.

\begin{tabular}{lll}
\hline Effector cells & Advantages & Disadvantages \\
\hline Lymphokine-activated killer (LAK) cells & $\begin{array}{l}\text { MHC-independent cytotoxicity } \\
\text { Easy preparation of cells }\end{array}$ & $\begin{array}{l}\text { Nonspecific killing } \\
\text { IL-2 related toxicities }\end{array}$ \\
\hline Natural killer (NK) cells & $\begin{array}{l}\text { MHC-independent cytotoxicity } \\
\text { Immediate response } \\
\text { Can be modified to target tumor antigens } \\
\text { genetically }\end{array}$ & Nonspecific killing \\
\hline$\gamma \delta$ T cells & $\begin{array}{l}\text { MHC-independent cytotoxicity } \\
\text { Immediate response }\end{array}$ & Nonspecific killing \\
\hline Tumor infiltrating lymphocytes (TILs) & Presumably tumor-specific killing & $\begin{array}{l}\text { Need T cells from tumor tissue } \\
\text { Technical difficulty to expand ex vivo }\end{array}$ \\
\hline $\mathrm{CD}^{+}$cytotoxic T lymphocytes & Tumor-specific killing & MHC class II-dependent cytotoxicity \\
\hline & Tumor-specific killing \\
CD8 ${ }^{+}$cytotoxic T lymphocytes & $\begin{array}{l}\text { Can be modified to target tumor antigens } \\
\text { genetically }\end{array}$ & MHC class I-dependent cytotoxicity \\
\hline $\begin{array}{l}\text { Genetically modified cytotoxic T } \\
\text { lymphocytes }\end{array}$ & $\begin{array}{l}\text { MHC-independent cytotoxicity } \\
\text { Rapid and elaborate tumor-specific killing }\end{array}$ & $\begin{array}{l}\text { Induction of antigen loss variants at } \\
\text { tumor recurrence } \\
\text { Possible overreactivity on same target } \\
\text { antigens expressed in normal tissue }\end{array}$ \\
\hline
\end{tabular}

antiglioma effect include IL-13R $\alpha 2$, human epidermal growth factor receptor 2 (HER2), epidermal growth factor receptor variant III (EGFRvIII), and erythropoietin-producing hepatocellular carcinoma A2 (EphA2) [19-22, 51].

Recruitment of lymphocytes is a key of immune response. Immune cells can infiltrate to malignant glioma at later stage of tumor growth with destruction of the BBB [52] and peripherally infused CTLs can enter the CNS in patients with malignant glioma [53]. Glioma-derived chemokines such as CCL2, CCL7, or CCL20 can mediate the recruitment of immune cells $[54,55]$.

\section{Antitumor Immune Responses of Effector Cells}

Effector cells used in ACT for the malignant glioma have developed from lymphokine-activated killer (LAK) cells with nonspecific cytotoxicity to more tumor-specific genetically engineered CTLs over time. The advantages and the disadvantages of the effector cells used in ACT for malignant glioma are summarized in Table 2.

3.1. LAK Cells. Autologous LAK cells are a mixture of IL2 activated $\mathrm{T}$ cells and natural killer (NK) cells and are generally obtained by culture of PBMCs in the presence of IL2. Major therapeutic limitation of these cells against tumors is that their lytic properties are not specifically directed against tumor cells. Autologous tumor cells were usually used as antigen source in ACT using LAK cells for malignant gliomas [56-59].

Although several clinical trials by intratumoral injection of LAK cells combined with IL- 2 for the glioblastoma patients have been carried out, most of their therapeutic effects have not shown a significant survival benefit [60-70]. In addition, the use of LAK cells in combination with IL-2 was not superior to the use of IL-2 alone in the phase III trial for other tumors [71]. Moreover, IL-2 related toxicities that emerged in some studies such as brain edema and aseptic meningitis have disturbed widespread use of this strategy for malignant gliomas $[63,65,70]$.

3.2. NK Cells. In contrast to adaptive immune responses, innate lymphocytes such as NK cells and $\gamma \delta$ T cells broadly recognize and immediately respond to a certain range of antigens in a MHC-independent fashion [72]. NK cells, $\mathrm{CD}^{-} \mathrm{CD} 6^{+}$lymphocytes, play potential role in cancer immunosurveillance as innate immune cells. They initially recognize the tumor cells via cellular stress or danger signals. Activated NK cells can directly kill tumor cells without MHC restriction, interact with DCs to facilitate the generation of antigen-specific CTL response by enhancing their antigen uptake and presentation, and induce $\mathrm{CD}^{+} \mathrm{T}$ cells to become CTLs by producing cytokines such as IFN- $\gamma$. Cytokines produced by NK cells can also regulate antitumor antibodies produced by B cells [73-75]. Both allogeneic and autologous IL-2 activated NK cells, furthermore, recognize and kill human glioblastoma cells with stem cell-like properties [76].

Although clinical trials with ACT using LAK cells did not show a significant clinical benefit for malignant gliomas as discussed above, recent advances in NK cell immunobiology and results in animal studies showing favorable antitumor effect in glioma-bearing mice treated with activated NK cells take a growing interest in ACT using activated NK cells again. NK cells can do traffic to the brain directly [77], so both peripheral and intratumoral route of administration are available in the treatment of malignant gliomas. In a rat glioma model, no therapeutic effect was observed in animals treated with intradermally injected paraformaldehyde-fixed tumor vaccine alone, but intratumoral injection of IL-2activated rat $\mathrm{NK}$ cells strongly enhanced antitumor effect 
of the vaccine [78]. Also, intracranial injection of cytokineinduced killer cells markedly inhibited intracranial xenotransplanted glioma growth in mice [79].

Safe antitumor response was shown in a clinical trial that exclusively used ex vivo expanded autologous NK cells to treat recurrent malignant glioma patients [80]. In this study, two $(22 \%)$ of the nine patients injected focally and intravenously showed partial response. Additionally, prolonged survival of the patients with malignant glioma treated by tumor-loaded DCs vaccine may be associated with NK cell response such as high level of circulating IFN- $\gamma$ and increased NK cell vaccine/baseline $(\mathrm{V} / \mathrm{B})$ ratio that was inversely correlated with TGF- $\beta 2 \mathrm{~V} / \mathrm{B}$ ratio [81]. These results suggest that a strategy of ACT using ex vivo activated NK cells following tumor-loaded vaccine can have a potent antiglioma effect as in animal studies.

Tumor cells, however, have various mechanisms to avoid $\mathrm{NK}$ cell recognition including the expression of MHC class I and ligands for inhibitory receptors on NK cells [82, 83]. In order to overcome this resistance of tumor cells to NKmediated cytotoxicity and enhance tumor recognition of NK cells, gene modification can be utilized. Antitumor activity of NK cells can be enhanced by genetic modification to highly express cytokines, Fc receptors, and/or chimeric antigen receptors (CARs) [84-86]. CAR directly recognizes tumor cell surface antigens and provides specificity of engineered cells regardless of antigen processing or $\mathrm{MHC}$-restricted presentation. Cytokine gene transfer such as IL-2 [87-89], IL-12 [88, 90], IL-15 [91-93], and stem cell factor (SCF) [94] induces NK cell proliferation and survival, and gene transfer of CARs against HERs/neu [95], carcinoembryonic antigen (CEA) [96], and CD33 [97] shows increased specificity [85] in vitro and in vivo studies. These results suggest ACT using genetically modified NK cells can be a challenge to patients with cancer including malignant gliomas.

NK cell-based immunotherapy has several potential limitations including the immunosuppressive microenvironment of the tumors. Activation of myeloid derived suppressor cells (MDSCs) and Tregs, especially, are known to be major

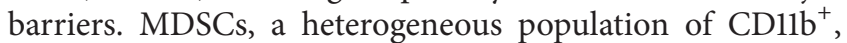
$\mathrm{Gr}-1^{+}$cells of immature myeloid origin, consist of myeloid progenitors and precursors of macrophages, granulocytes, and DCs and have a strong ability to suppress a variety of T cell and NK cell functions [98-100]. MDSCs can also modulate the induction of Tregs [101, 102]. MDSCs increase in malignant glioma-bearing mice [77] and effectively inhibit NK cell-mediated tumor suppression. Circulating number of these tumor suppressor cells also increases in the patients with malignant gliomas $[103,104]$. Although there have been no published studies on human glioma-infiltrating MDSCs to date, many preclinical studies to improve antitumor effect by reducing MDSCs in tumor-bearing animal models have been carried out $[105,106]$.

Tregs are potential inhibitors of NK cell activity in malignant gliomas [107]. Tregs directly inhibit NKG2Dmediated NK cell cytotoxicity, effectively suppressing NK cell-mediated tumor rejection by a TGF- $\beta$ dependent mechanism and independent of IL-10 and depletion of Tregs via NKG2D before NK cell activation markedly enhances NK cell-mediated suppression of tumor growth and metastases in animal studies [108]. Tregs also decrease NK cell cytotoxicity and downregulate the IFN- $\gamma$ secretion of NK cell responding to IL-12 activation in a TGF- $\beta$ dependent manner [109]. Elimination or inhibition of these immunosuppressive cells, therefore, can improve the antitumor effect of ACT using NK cells.

3.3. $\gamma \delta \mathrm{T}$ Cells. $\gamma \delta \mathrm{T}$ cells are a subpopulation of $\mathrm{T}$ lymphocytes, which express T-cell receptors (TCRs) consisting of one $\gamma$ chain and one $\delta$ chain. Unlike the conventional $\alpha \beta$ $\mathrm{T}$ cells that recognize only MHC-related antigens, $\gamma \delta \mathrm{T}$ cells can broadly recognize and immediately respond to a range of antigens in a MHC-independent manner.

$\gamma \delta$ T cells have potent cytotoxic activity against malignant glioma cells $[110,111]$. Antiglioma effect of human $\gamma \delta \mathrm{T}$ cells can be increased by the addition of IL-12 [112, 113]. Intracranial infusion of expanded and activated $\gamma \delta$ T cells can mediate killing of new or established glioblastoma xenografts and reduce tumor progression [114]. Ex vivo expanded and activated $\gamma \delta$ T cells from both patients and healthy volunteers can recognize and kill glioblastoma cell lines and primary glioblastoma culture cells, but $\gamma \delta$ T cell counts and mitogenstimulated proliferative response of $\gamma \delta$ T cells are markedly decreased in glioblastoma patients prior to treatment, suggesting that allogeneic therapy could be a reasonable option in adoptive $\gamma \delta$ T cell immunotherapy [115].

Despite of the theoretical basis of $\gamma \delta \mathrm{T}$ cell-based immunotherapy, there have been no clinical studies designed to assess the immunotherapeutic potential of $\gamma \delta$ cell therapy against malignant gliomas to date. A recent report that gene modified $\gamma \delta$ T cells have greater cytotoxicity to temozolomide (TMZ) resistant glioblastoma cell lines in the presence of TMZ than unmodified cells [116] suggests combined TMZ resistant $\gamma \delta \mathrm{T}$ cell immunotherapy and high dose TMZ chemotherapy could be a new therapeutic challenge to the glioblastoma patients.

3.4. TILs. Tumor infiltrating lymphocytes (TILs) are effector cells presumably thought to be able to recognize and respond to the specific tumor antigens because they are already present in the tumor. Although antitumor activity of endogenous TILs may not be sufficient to conquer tumor-induced immunosuppressive environment, ex vivo expansion of these cells may overcome this immunologic barrier and be a tool of ACT for tumors. Ex vivo expanded TILs have the properties to proliferate in vivo and display functional activity and trafficking to tumor [117]. Significantly increased antitumor activities of ex vivo expanded TILs therapy have been shown in clinical trials for melanoma especially in combination of lymphodepletion with intensive chemoradiation $[118,119]$.

It is difficult, however, to expand TILs from tumor tissues in most cancers including malignant glioma except melanomas [120]. In a pilot study exclusively performed to date against patients with recurrent malignant gliomas that were treated with intratumoral infusion of ex vivo expanded autologous TILs with IL-2, one of six patients showed complete remission, two had partial responses, and three died of 
tumor progression [56]. The cytotoxic activity of TILs against autologous tumors in vitro was variously dependent on the patients and was not correlated with the clinical outcome in this study. These results suggest that clinical benefit from ACT for malignant gliomas using ex vivo expanded TILs may be limited.

3.5. Antigen-Specific CTLs. Antigen-specific CTLs commonly generated by ex vivo antigen stimulation of PBMCs with autologous inactivated tumor cells have potent antitumor immune response compared with $\mathrm{T}$ cell response to endogenous stimulation. These CTLs are also able to migrate to antigen-expressed tumor cells following administration and have durable antitumor effect by memory T cells. Ex vivo expansion of CTLs for strong priming of T cells with antigens and for rapid increase of effector $\mathrm{T}$ cell numbers makes these cells feasible to be used in ACT for cancers.

To date, 4 phase I trials to evaluate CTLs generated from PBMCs $[57-59,121]$ and 3 phase I and 2 pilot studies examining CTLs obtained by lymphocytes from tumor draining lymph nodes or PBMCs after vaccination with irradiated autologous tumor cells [53, 122-125] against malignant gliomas have been described. Total 9 clinical trials of ACT using antigen-specific CTLs showed 2 complete response (CR), 26 partial response (PR), and 16 stable disease (SD) in 87 patients with malignant gliomas ( 65 glioblastoma). Data from 49 patients with glioblastoma exclusively in 8 trials except a study that did not describe the results from the distinguished tumor grade [125] demonstrated a result of no $\mathrm{CR}, 11 \mathrm{PR}$, and $6 \mathrm{SD}$. A pilot study for 19 patients with recurrent malignant gliomas (16 glioblastoma) that did not distinguish tumor grade in treatment outcome displayed a favorable result of 1 CR, 7 PR, and 9 SD [125]. More improved median survival of 12 months after tumor recurrence compared with 6 months for controls and a positive correlation between increased survival and delayed-type hypersensitivity response were described in this study [125]. Similarly, a positive correlation between CD4/CD8 composition of infused cells and clinical response was reported [124]. Most other trials, however, did not show survival benefit and a clear association between the concentration of injected $\mathrm{T}$ cells and clinical outcome.

3.6. $\mathrm{CD}^{+} \mathrm{T}$ Cells. $\mathrm{CD} 4^{+} \mathrm{T}$ cells contribute to the immunologic antitumor activity through their ability to mediate tumor cell destruction independent of $\mathrm{CD}^{+} \mathrm{T}$ cells as well as help activate $\mathrm{CD}^{+} \mathrm{T}$ cells classically [126-128]. Identification of MHC class II-restricted isotopes derived from several TAAs including melanoma differentiation antigens and several cancer-testis antigens becomes feasible to generate antigen-specific $\mathrm{CD}^{+}{ }^{+} \mathrm{T}$ cells which can be used in ACT [129-131]. Several preclinical studies have described antitumor effect of ACT using $\mathrm{CD}^{+} \mathrm{T}$ cell population, and CD4+ $\mathrm{T}$ cells have cytolytic activity dependent on class II-restricted recognition of tumors [132-134]. In a recent early-phase dose escalation study of ACT for patient with metastatic melanoma using $\mathrm{CD} 4^{+} \mathrm{T}$ cell clones, the patients experienced partial responses including a case of a complete durable response $[128,135]$.
TABLE 3: Genetic modification of T cells to improve the efficacy of ACT for cancers.

\begin{tabular}{lc}
\hline & References \\
\hline Enhanced specificity & {$[16,17,136]$} \\
Expression of $\alpha \beta$ TCR & {$[18-22]$} \\
Expression of CARs & {$[23-25,137]$} \\
Coexpression of costimulatory molecules & \\
Increased survival and proliferation & {$[138-141]$} \\
Expression of proliferative cytokines & {$[142-144]$} \\
Expression of antiapoptotic genes & {$[145-148]$} \\
Ectopic expression of gene for telomere & \\
elongation (hTERT) & {$[149-152]$} \\
Enhanced trafficking & \\
Expression of chemokine receptors & {$[153-156]$} \\
Enhanced trafficking & {$[157]$} \\
Expression of negative TGF- $\beta$ receptor & \\
Downregulation of Fas & {$[116]$} \\
Integration with conventional therapy & \\
Expression of chemoresistant genes &
\end{tabular}

\section{Enhancement of Tumor-Specific T Cell Function}

4.1. Genetically Modified T Cells. Recently, gene modification of $\mathrm{T}$ cells has been developed for enhancing the efficacy of ACT. Gene engineering of T cells by a variety of gene transfer techniques is able to allow $\mathrm{T}$ cells to make them more resistant to immune evasion mechanisms of tumor cells or modify the tumor environment to make it less inhibitory to $\mathrm{T}$ cell activation and effector function [9] (Table 3). Retroviral or lentiviral vectors are usually used for gene delivery $[14,15]$.

Two most common approaches can be used for enhancement of T cell specificity: (a) gene modification with TCR variable $\alpha$ and $\beta$ chains cloned from high affinity TAAspecific T cells and (b) insertion of chimeric antigen receptors (CARs) that recognize tumors through single-chain variable fragment $(\mathrm{scFv})$ isolated from TAA-specific Abs.

Genes encoding TCRs of T cells isolated from patients showing an excellent response to ACT can be cloned into viral vectors and then be used to alter T cells from other patients with matching HLA restriction elements to be treated [17]. These genes can also be isolated from humanized mice that have been primed to recognize TAAs. Humanized mice that have been cloned human MHC class I or class II molecules can express human MHC molecules and can be immunized with human TAAs of interest. Mouse $\mathrm{T}$ cells specific for certain MHC-restricted epitope can then be isolated, and their TCR genes are cloned into viral vectors that can be used to genetically modify $\mathrm{T}$ cells from the patient $[17,158]$.

Some clinical studies for patients with metastatic melanoma using $\mathrm{T}$ cells genetically modified with tumor antigen-specific $\mathrm{T}$ cell receptors for patient with melanoma have been conducted $[16,17]$. In a recent clinical study assessing ACT using a high-avidity TCR recognized MART-1 and gp 100 for patients with metastatic melanoma, cancer 
regression was seen in $30 \%$ and $19 \%$ of patients who received the human or mouse TCR, but patients exhibited destruction of normal melanocytes throughout the body including skin, eye, and ear as the result of CTL responses to cognate antigen-containing cells [17]. No clinical study for malignant gliomas, however, has been performed to date. This procedure allows the rapid production of TAA-specific $\mathrm{T}$ cells but has a basic limitation that $\mathrm{T}$ cells engineered by this procedure can mainly recognize antigens that have processed and presented in MHC-restricted patterns.

An alternative approach to overcome this limitation is the use of CARs, genes encoding monoclonal antibody chains specific for TAAs [18]. T cells modified with CARs can be directed toward any antigen expressed on the cell surface because CARs provide $\mathrm{T}$ cell activation regardless of MHC-restricted presentation. CARs are synthetic molecules that consist of an extracellular antigen binding domain that usually contains the heavy and light chain variable regions of a monoclonal antibody, referred to as a single chain Fc $(\mathrm{scFv})$ molecule, joined to transmembrane and cytoplasmic signaling domains derived from $\mathrm{CD} 3-\zeta$ chain or Fc receptor $\gamma$ chains $(\mathrm{FcR} \gamma)$ and from costimulatory molecules. Engineered $\mathrm{T}$ cells activated by both tumor-specific TCR and costimulatory molecules such as CD28, 4-1BB, OX40, and inducible costimulator (ICOS) have enhanced antitumor activity to tumors [23-25, 159, 160].

$\mathrm{T}$ cells and expressing CARs for the glioma-specific antigens including IL-13R $\alpha 2$, HER2, EGFRvIII, and EphA2 show potent antiglioma activity in preclinical animal studies [19-22, 51]. In a study, $\mathrm{T}$ cells from glioblastoma patients could be modified with HER2-specific chimeric antigen receptors to produce effector cells and killed autologous HER2-postive glioblastoma cells including CD133-positive glioblastoma stem cells. These HER2-specific T cells also had a potent antitumor activity against autologous tumors in an orthotopic xenogeneic SCID mouse model [20]. Recently, cytomegalovirus has emerged as a target for the treatment of malignant gliomas. Expression of genes unique to cytomegalovirus (CMV) in malignant gliomas has raised the possibility of CMV-specific T cells as a therapeutic tool [161164]. Data from a recent clinical study to evaluate antiglioma response of ACT using CMV-specific T cells in combination with TMZ into a patient with recurrent glioblastoma showing a long-term disease free survival [164] suggest CMV can be a challenging target of ACT for malignant gliomas and provide an important clue for further evaluation of combined ACT and TMZ chemotherapy.

Although clinical experience of ACT using $\mathrm{T}$ cells expressing TAA-specific CARs is limited, therapeutic limitations of these cells have emerged. In a clinical study targeting three glioblastoma patients treated by intracranial adoptive transfer of autologous IL-13R $\alpha 2$-specific CTL clones, safe antiglioma responses against antigen positive $\mathrm{CD}_{133^{+}}$glioma stem cells as well as antigen positive glioma cells were documented, but IL-13R $\alpha 2$ antigen was not expressed in the eventually recurred tumor [165]. Immune escape like these antigen loss variants also can be presented in peptide vaccination targeting EGFRvIII in patients with glioblastoma
[166], so antigen loss variants may be a major mechanism responsible for tumor progression.

In addition, there are safety concerns with regard to HER2-targeted $\mathrm{T}$ cell therapy. A patient administered $\mathrm{T}$ cells with a CAR recognizing ERBB2 died of respiratory distress probably due to cytokine storm by massive release from ERBB2 expressing $\mathrm{T}$ cells localized to the lung with recognition of low levels of ERBB2 on lung epithelial cells [167].

Genetic engineering can increase effector function of $\mathrm{T}$ cells by modification of tumor environment as well as enhanced $\mathrm{T}$ cell specificity to malignant gliomas. Other strategies for cancers to increase $\mathrm{T}$ cell effector function through genetic modification are described (Table 3 ).

4.2. Prolongation of $T$ Cell Survival. Identification of $T$ cell populations that can reproducibly survive in vivo for increased antitumor effect in ACT is also important. CD8 ${ }^{+}$ $\mathrm{T}$ cells have been described as naive cells and four antigenexperienced subtypes according to the differentiation status: T memory stem cell $\left(\mathrm{T}_{\mathrm{SCM}}\right)$, central memory $\left(\mathrm{T}_{\mathrm{CM}}\right)$, effector memory $\left(\mathrm{T}_{\mathrm{EM}}\right)$, and differentiated effector $\mathrm{T}$ cells [168]. T cell differentiation is inversely correlated with antitumor effect in ACT for cancer $[158,169]$. Preclinical studies in human $\mathrm{T}$ cells suggest that arrested differentiation via reducing IL-2 concentration in culture condition [170-172] and inhibitors of the WNT signaling pathway $[173,174]$ can lead to enrichment of less differentiated memory $\mathrm{T}$ cells with high replicative potential.

Recently isolated $\mathrm{T}_{\mathrm{SCM}}$ cells in mouse model, the least differentiated memory subset, have a preferential intrinsic capacity for long-term in vivo persistence and for selfrenewal, and a multipotent ability to derive $\mathrm{T}_{\mathrm{CM}}, \mathrm{T}_{\mathrm{EM}}$, and effector $\mathrm{T}$ cells in response to antigen reexposure $[168,175]$. $\mathrm{T}_{\mathrm{SCM}}$ cells have been shown to be more effective than $\mathrm{T}_{\mathrm{CM}}$ cells which were more effective than $\mathrm{T}_{\mathrm{EM}}$ cells in terms of ACT against tumors in various preclinical studies [135, $158,169,176] . \mathrm{T}_{\mathrm{SCM}}$ cells consistently express a surface marker typically found on naive $\mathrm{T}$ cells and also express stem cell antigen-1 (Sca-1), B cell lymphoma 2 (Bcl-2), the $\beta$ chain of the IL-2 (IL-2R $\beta$ ), and the chemokine (C-X-C motif) receptor CXCR3 $[168,177]$. The identification and ex vivo expansion to minimize corruption of a similar human stem cell-like memory $\mathrm{T}$ cells may be important in the development of ACT, and these cells may play a greater role in human future ACT strategies for patients with cancer.

\section{Modification of the Host Environment}

5.1. Lymphodepletion. Lymphoid cells have an independent homeostatic regulation of resting and memory cell compartments, so a rapid proliferation of remaining or infused lymphocytes happens to recover normal lymphocyte numbers after periods of lymphopenia $[178,179]$. During homeostasisinduced $\mathrm{T}$ cell proliferation, naive $\mathrm{T}$ cells stably acquire the cell surface markers and functional properties of memory $\mathrm{T}$ cells capable of rapid and intense response to antigen, and these homeostasis-stimulated memory $\mathrm{CD}^{+} \mathrm{T}$ cells 
respond to lower doses of antigen than naive cells [180]. Considering that this recovery is mediated by MHC dependent recognition, that memory $\mathrm{CD}^{+} \mathrm{T}$ cells respond in the reduced activation threshold of tumor-specific cells, and that proliferated $\mathrm{T}$ cells have effector functions, administration of tumor specific antigens in the form of a vaccine or ex vivo expanded adoptive $\mathrm{T}$ cell transfer during this recovery period can induce disproportionate enhancement of effector cell populations that have autoimmune responses against tumorassociated self-antigens, leading to increased antitumor effect of ACT [180-184].

The induction of immunodepleting condition in patients before $\mathrm{T}$ cell-based immunotherapy can be achieved by use of total body irradiation (TBI) or nonmyeloablative chemotherapy. Data in clinical trials using these approaches have been shown to enhance the efficacy of ACT $[118,119,185-$ 188] such as melanocyte-directed autoimmunity noted in some patients with metastatic melanoma treated by these approaches $[118,189]$.

Another therapeutic advantage of lymphodeletion prior to immunotherapy is the elimination of major immunosuppressive cellular elements within the tumor microenvironment such as MDSCs and Tregs. As described above, MDSCs are found in most patients with advanced cancers [103, 190192], so elimination or blockade of the immunosuppressive functions of MDSCs can provoke an enhanced antitumor effect of immunotherapeutic strategies for tumors $[193,194]$. MDSCs can also modulate the induction of Tregs [101, 102]. Tregs that play a two-directional role in controlling autoimmunity and $\mathrm{T}$ cell homeostasis can selectively suppress spontaneous lymphopenia-induced naive $\mathrm{T}$ cell proliferation [195] and actually enhance immune function by optimization of the conventional T cell diversity [196]. Tregs are increased after total body irradiation and inhibit the induction of effector $\mathrm{T}$ cells during recovery period from lymphopenia, whereas depletion of Tregs strongly inhibits tumor progression in animal study [197]. In a recent clinical pilot study, anti-IL-2R $\alpha$ MAb daclizumab treatment combined with EGFRvIII-targeted peptide vaccination could deplete Tregs safely and significantly in patients with glioblastoma treated with lymphodepleting TMZ correlating with enhanced antitumor immunity [198].

Additionally, ACT can be enhanced by the increased depletion of endogenous cells that compete for homeostatic cytokines such as IL-7 and IL-15 [119], by the promotion of the expansion and function of adoptively transferred antitumor CD8 T cells through hematopoietic stem cells [199], and by the increased functionality of adoptively transferred $\mathrm{T}$ cells mediated by TBI-evoked microbial translocation [200].

5.2. Inhibition of Immunosuppressive Environment. Elimination or blockade of immunosuppressive molecules of human cancers can enhance the antitumor efficacy of ACT. The challengeable targets for the treatment of malignant gliomas can be TGF- $\beta$, Tregs, and signal transducer and activator of transcription 3 (STAT3).

TGF- $\beta$ is a potent immunodepressant and blocking of TGF- $\beta$ effects on T cells can improve antitumor efficacy of
T cells after ACT for malignancies [153, 154, 201]. Administration of TGF- $\beta$ receptor I kinase inhibitor increases tumor infiltration by NK, T cells and macrophage and increases survival in glioma-bearing mice $[202,203]$. The most clinically advanced strategy to elicit TGF- $\beta$ in gliomas is the use of intratumorally administered TGF- $\beta 2$ antisense oligonucleotides using convection-enhanced delivery [204]. Phase II study that evaluated the efficacy and safety of trabedersen (TGF- $\beta 2$ antisense oligonucleotides) administered intratumorally by convection-enhanced delivery compared with standard chemotherapy in patients with recurrent malignant gliomas showed a superior safety and a trend for superiority in 2-year survival rate of patients with anaplastic astrocytoma compared to chemotherapy [205]. However, further clinical study discontinued during the phase III trial unfortunately. TGF- $\beta$ also influences the development, maintenance, and induction of Tregs, while disruption of TGF- $\beta$ signaling prevents the generation of Tregs [206, 207].

Tregs have an important role in maintaining selftolerance and in the prevention of autoimmunity physiologically, and increased Tregs fractions with $\mathrm{CD}^{+}{ }^{+} \mathrm{T}$ cell defects inducing decreased $\mathrm{T}$ cell responses are seen in patients with gliomas [208]. Characteristics of Tregs in both mice and humans are the high expression of surface markers CD25 (IL-2R- $\alpha$-chain), constitutive expression of cytotoxic T-lymphocyte antigen 4 (CTLA-4), overexpression of glucocorticoid-induced tumor necrosis factor receptorrelated protein (GITR), and the expression of the transcriptional regulator Foxp3 $[209,210]$. These molecules can be therapeutic targets for depleting Tregs to improve ACT for gliomas.

Strategies such as anti-CD25 antibody and CD25-specific immunotoxin [211] employed to reduce Treg function target the constitutively expressed cell surface marker, CD25. IL$2 \mathrm{R} \alpha$ (CD25) blocking with anti-IL-2 $\alpha$ (anti-CD25 antibody) daclizumab combining glioma antigen (CMV or EGFRvIII) specific vaccination during lymphopenia selectively depletes Tregs in mice and humans [198, 212].

Another possible approach to reduce Tregs in glioma is via CTLA- 4 blockade. CTLA- 4 is a transmembrane protein that binds to ligands B7-1 and B7-2 on APCs and is constitutively expressed on Tregs, acting as a potent negative regulator of $\mathrm{T}$ cell activation. Anti-CTLA-4 antibodies have shown potential therapeutics for gliomas [213], and combining sequential immunotherapy with GM-CSF expressing irradiated glioma cell vaccine synergistically prolongs survival in mice-bearing gliomas [214].

STAT3 is generally overexpressed in cancers including malignant gliomas and plays an important role in negative regulation of antitumor immunity. STAT3 regulates the expression of TGF- $\beta$ and IL-10, cytokine related to the presence of Tregs in tumors, so STAT3 can be a target for depleting Tregs. Inhibition of STAT3 promotes the activity of NK and T cells on cancer cells $[215,216]$. STAT3 inhibition was shown to reverse the immunosuppressive environment in malignant gliomas [217] and to promote the efficacy of ACT in a murine glioma model [216]. Furthermore, adoptive transfer of $\mathrm{T}$ cells that transfected miRNAs, gene transcripts modulating STAT3 signaling, exerts potent antiglioma 
therapeutic effects in genetically engineered murine glioblastoma models and enhances effector responses in the local tumor microenvironment [218]. Additionally, a low dose metronomic TMZ therapy can induce Treg depletion [219] and inhibit trafficking of Tregs into the glioma microenvironment [220].

IDO is an intracellular enzyme that catalyzes oxidative catabolism of tryptophan [221, 222]. T cell proliferation is arrested when exposed to tryptophan shortage evoked by IDO, and most human tumors including gliomas evade cellular immune response through the constitutively expressed IDO [223]. Consequently, IDO expressing tumor cells are able to inhibit tumor specific T cell response [224]. Expression of IDO in APCs also allows macrophages and DCs to inhibit $\mathrm{T}$ cell proliferation [225] and expand potent autologous Tregs [226]. Inhibition of IDO can improve $\mathrm{T}$ cell therapy for cancers [227-229]. In addition, molecular targeted therapy with imatinib can potentiate antitumor cell responses in gastrointestinal tumor through the inhibition of IDO [230].

Recently, IDO emerged as therapeutic target for the treatment of gliomas [231]. IDO expression in glioma is associated with malignant progression [232] and a significant decrease of overall survival in patients [233]. IDO expression in brain tumors also increases the recruitment of Tregs in mouse model $[233,234]$.

\section{Combining T Cell Therapy}

Combining immunotherapy with cytotoxic chemotherapy or targeted therapy can promote the therapeutic potential for the treatment of cancers in comparison with the use of either treatment alone because abundant antigens can be released from the dying tumor cells and increased effector cell capacity to recognize and kill tumor cells can be induced by cytotoxic chemotherapeutic agents $[235,236]$. This antigen processing can lead to the priming of adoptively transferred tumor-specific T cells as well as the activation of endogenous tumor-specific T cells. Chemotherapy can enhance tumor cell susceptibility to CTL-mediated cytotoxicity during cancer immunotherapy, increasing the efficacy of tumor-specific $\mathrm{T}$ cell activation in mice with advanced cancer [237, 238]. Furthermore, chemotherapy (dacarbazine, temozolomide, and cisplatin) induces intratumoral expression of $\mathrm{T}$ cell attracting chemokines [239]. Combined TMZ chemotherapy and immunotherapy with DC-based vaccines can lead to the enhancement of antitumor immunity through increased tumor-specific immune responses via the cross-priming of apoptotic tumor cell death as well as suppression of Tregs in glioma bearing mice [26] and showed to be beneficial for survival in a phase II trial in patients with newly diagnosed glioblastoma [27].

Oncogene addiction is a phenomenon in which the survival of cancer cells depends on an activated oncogene or inactivation of tumor suppressor gene and is an ideal potential target for molecular targeted therapy in human cancers [240, 241]. Tumor cell death after oncogene addiction may provide antigenic stimulation of $\mathrm{T}$ cells, and oncogene addiction may also reduce the production of immunosuppressive molecules by tumor cells, promising increased antitumor efficacy of combining ACT with molecular targeted therapy for cancers including gliomas [242]. Actually, BRAF inhibition can induce the enhanced $\mathrm{T}$ cell recognition and subsequent $\mathrm{T}$ cell response on melanoma cells [243], and BRAF inhibitor vemurafenib improves the antitumor activity of ACT for advanced melanoma in mice [244].

In vivo expansion of $\mathrm{T}$ cells by vaccination has limitation due to the immunosuppressive environment of the tumor, and clinical trials using vaccine alone do not have significant antitumor effect [245]. Combining T cell therapy and vaccination can also be an alternative approach to facilitate expansion and maintenance of $\mathrm{T}$ cells that survived in poor immunogenic tumor environment.

\section{Future Directions}

$\mathrm{T}$ cells used in ACT for malignant gliomas have been developed and will be more advanced to overcome immune evasion mechanisms and to survive in immunosuppressive environment employed by the tumor.

Future efforts will need to focus on identification of patient-specific tumor antigens through highly personalized approach, development of efficient lymphodepleting regimens prior to $\mathrm{T}$ cell transfer, and effective combination with other therapeutic modalities such as molecular agents targeting personalized oncogene addiction and potent host immune modulators.

\section{Conflict of Interests}

The authors declare that there is no conflict of interests regarding the publication of this paper.

\section{References}

[1] S. J. Han, C. Zygourakis, M. Lim, and A. T. Parsa, "Immunotherapy for Glioma. Promises and challenges," Neurosurgery Clinics of North America, vol. 23, no. 3, pp. 357-370, 2012.

[2] P.-Y. Dietrich, V. Dutoit, N. N. T. Thang, and P. R. Walker, “Tcell immunotherapy for malignant glioma: toward a combined approach," Current Opinion in Oncology, vol. 22, no. 6, pp. 604610,2010

[3] D. A. Mitchell, P. E. Fecci, and J. H. Sampson, "Adoptive immunotherapy for malignant glioma," Cancer Journal, vol. 9, no. 3, pp. 157-166, 2003.

[4] D. B. Paul and C. A. Kruse, "Immunologic approaches to therapy for brain tumors," Current Neurology and Neuroscience Reports, vol. 1, no. 3, pp. 238-244, 2001.

[5] V. Schirrmacher, H.-J. Schild, B. Guckel, and P. Von Hoegen, "Tumour-specific CTL response requiring interactions of four different cell types and recognition of MHC class I and class II restricted tumour antigens," Immunology and Cell Biology, vol. 71, pp. 311-326, 1993.

[6] A. F. Ochsenbein, P. Klenerman, U. Karrer et al., "Immune surveillance against a solid tumor fails because of immunological ignorance," Proceedings of the National Academy of Sciences of the United States of America, vol. 96, no. 5, pp. 2233-2238, 1999. 
[7] G. Parmiani, "Tumor immunity as autoimmunity: tumor antigens include normal self proteins which stimulate anergic peripheral T cells," Immunology Today, vol. 14, no. 11, pp. 536538, 1993.

[8] D. E. Speiser, R. Miranda, A. Zakarian et al., "Self antigens expressed by solid tumors do not efficiently stimulate naive or activated T cells: implications for immunotherapy," The Journal of Experimental Medicine, vol. 186, no. 5, pp. 645-653, 1997.

[9] A. M. Leen, C. M. Rooney, and A. E. Foster, "Improving T cell therapy for cancer," Annual Review of Immunology, vol. 25, pp. 243-265, 2007.

[10] L. M. Liau, R. M. Prins, S. M. Kiertscher et al., "Dendritic cell vaccination in glioblastoma patients induces systemic and intracranial T-cell responses modulated by the local central nervous system tumor microenvironment," Clinical Cancer Research, vol. 11, no. 15, pp. 5515-5525, 2005.

[11] H. Okada, F. S. Lieberman, K. A. Walter et al., "Autologous glioma cell vaccine admixed with interleukin- 4 gene transfected fibroblasts in the treatment of patients with malignant gliomas," Journal of Translational Medicine, vol. 5, article 67, 2007.

[12] S. Phuphanich, C. J. Wheeler, J. D. Rudnick et al., "Phase I trial of a multi-epitope-pulsed dendritic cell vaccine for patients with newly diagnosed glioblastoma," Cancer Immunology, Immunotherapy, vol. 62, no. 1, pp. 125-135, 2013.

[13] C. J. Wheeler, K. L. Black, G. Liu et al., "Vaccination elicits correlated immune and clinical responses in glioblastoma multiforme patients," Cancer Research, vol. 68, no. 14, pp. 59555964, 2008.

[14] S. Cavalieri, S. Cazzaniga, M. Geuna et al., "Human T lymphocytes transduced by lentiviral vectors in the absence of TCR activation maintain an intact immune competence," Blood, vol. 102, no. 2, pp. 497-505, 2003.

[15] O. J. Finn, D. A. Persons, K. M. Bendt, L. Pirami, and P. Ricciardi, "Retroviral transduction of protein kinase C- $\gamma$ into cytotoxic T lymphocyte clones leads to immortalization with retention of specific function," The Journal of Immunology, vol. 146, no. 4, pp. 1099-1103, 1991.

[16] R. A. Morgan, M. E. Dudley, J. R. Wunderlich et al., "Cancer regression in patients after transfer of genetically engineered lymphocytes," Science, vol. 314, no. 5796, pp. 126-129, 2006.

[17] L. A. Johnson, R. A. Morgan, M. E. Dudley et al., "Gene therapy with human and mouse $\mathrm{T}$-cell receptors mediates cancer regression and targets normal tissues expressing cognate antigen," Blood, vol. 114, no. 3, pp. 535-546, 2009.

[18] Z. Eshhar, T. Waks, G. Gross, and D. G. Schindler, "Specific activation and targeting of cytotoxic lymphocytes through chimeric single chains consisting of antibody-binding domains and the $\gamma$ or $\zeta$ subunits of the immunoglobulin and T-cell receptors," Proceedings of the National Academy of Sciences of the United States of America, vol. 90, no. 2, pp. 720-724, 1993.

[19] S. S. Bullain, A. Sahin, O. Szentirmai et al., "Genetically engineered T cells to target EGFRvIII expressing glioblastoma," Journal of Neuro-Oncology, vol. 94, no. 3, pp. 373-382, 2009.

[20] N. Ahmed, V. S. Salsman, Y. Kew et al., "HER2-specific T cells target primary glioblastoma stem cells and induce regression of autologous experimental tumors," Clinical Cancer Research, vol. 16, no. 2, pp. 474-485, 2010.

[21] K. K. Chow, S. Naik, S. Kakarla et al., "T cells redirected to EphA2 for the immunotherapy of glioblastoma," Molecular Therapy, vol. 21, no. 3, pp. 629-637, 2013.

[22] K. S. Kahlon, C. Brown, L. J. N. Cooper, A. Raubitschek, S. J. Forman, and M. C. Jensen, "Specific recognition and killing of glioblastoma multiforme by interleukin 13-zetakine redirected cytolytic T cells," Cancer Research, vol. 64, no. 24, pp. 9160-9166, 2004.

[23] D.-G. Song, Q. Ye, C. Carpenito et al., "In vivo persistence, tumor localization, and antitumor activity of CAR-engineered $\mathrm{T}$ cells is enhanced by costimulatory signaling through CD137 (4-1BB)," Cancer Research, vol. 71, no. 13, pp. 4617-4627, 2011.

[24] C. M. Kowolik, M. S. Topp, S. Gonzalez et al., "CD28 costimulation provided through a CD19-specific chimeric antigen receptor enhances in vivo persistence and antitumor efficacy of adoptively transferred T cells," Cancer Research, vol. 66, no. 22, pp. 10995-11004, 2006.

[25] A. A. Hombach and H. Abken, "Costimulation by chimeric antigen receptors revisited the $\mathrm{T}$ cell antitumor response benefits from combined CD28-OX40 signalling," International Journal of Cancer, vol. 129, no. 12, pp. 2935-2944, 2011.

[26] T.-G. Kim, C.-H. Kim, J.-S. Park et al., "Immunological factors relating to the antitumor effect of temozolomide chemoimmunotherapy in a murine glioma model," Clinical and Vaccine Immunology, vol. 17, no. 1, pp. 143-153, 2010.

[27] C. E. Fadul, J. L. Fisher, T. H. Hampton et al., "Immune response in patients with newly diagnosed glioblastoma multiforme treated with intranodal autologous tumor lysatedendritic cell vaccination after radiation chemotherapy," Journal of Immunotherapy, vol. 34, no. 4, pp. 382-389, 2011.

[28] P. B. MEDAWAR, "Immunity to homologous grafted skin; the fate of skin homografts," British Journal of Experimental Pathology, vol. 29, no. 1, pp. 58-69, 1948.

[29] M. Poltorak, S. Logan, and W. J. Freed, "Intraventricular xenografts: chronic injection of antibodies into the CSF provokes granulomatosis reactions but Ia antibodies do not enhance graft survival," Regional Immunology, vol. 2, no. 4, pp. 197-202, 1989.

[30] P. A. Ludowyk, D. O. Willenborg, and C. R. Parish, "Selective localisation of neuro-specific $\mathrm{T}$ lymphocytes in the central nervous system," Journal of Neuroimmunology, vol. 37, no. 3, pp. 237-250, 1992.

[31] H. Wekerle, D. Sun, R. L. Oropeza-Wekerle, and R. Meyermann, "Immune reactivity in the nervous system: modulation of Tlymphocyte activation by glial cells," The Journal of Experimental Biology, vol. 132, pp. 43-57, 1987.

[32] H. F. Cserr, C. J. Harling-Berg, and P. M. Knopf, "Drainage of brain extracellular fluid into blood and deep cervical lymph and its immunological significance," Brain Pathology, vol. 2, no. 4, pp. 269-276, 1992.

[33] I. F. Parney, "Basic concepts in glioma immunology," Advances in Experimental Medicine and Biology, vol. 746, pp. 42-52, 2012.

[34] I. Yang, S. J. Han, G. Kaur, C. Crane, and A. T. Parsa, “The role of microglia in central nervous system immunity and glioma immunology," Journal of Clinical Neuroscience, vol. 17, no. 1, pp. 6-10, 2010.

[35] A.-H. Wu, J. Xiao, L. Anker et al., "Identification of EGFRvIIIderived CTL epitopes estricted by HLA A0201 for dendritic cell based immunotherapy of gliomas," Journal of Neuro-Oncology, vol. 76, no. 1, pp. 23-30, 2006.

[36] M. Sasaki, K. Nakahira, Y. Kawano et al., "MAGE-E1, a new member of the melanoma-associated antigen gene family and its expression in human glioma," Cancer Research, vol. 61, no. 12, pp. 4809-4814, 2001.

[37] D. L. Scarcella, C. W. Chow, M. F. Gonzales, C. Economou, F. Brasseur, and D. M. Ashley, "Expression of MAGE and 
GAGE in high-grade brain tumors: a potential target for specific immunotherapy and diagnostic markers," Clinical Cancer Research, vol. 5, no. 2, pp. 335-341, 1999.

[38] R. Ueda, Y. Iizuka, K. Yoshida, T. Kawase, Y. Kawakami, and M. Toda, "Identification of a human glioma antigen, SOX6, recognized by patients'sera," Oncogene, vol. 23, no. 7, pp. 14201427, 2004.

[39] G. Liu, H. Ying, G. Zeng, C. J. Wheeler, K. L. Black, and J. S. Yu, "HER-2, gp100, and MAGE-1 are expressed in human glioblastoma and recognized by cytotoxic T cells," Cancer Research, vol. 64, no. 14, pp. 4980-4986, 2004.

[40] G. Liu, H. T. Khong, C. J. Wheeler, J. S. Yu, K. L. Black, and H. Ying, "Molecular and functional analysis of tyrosinase-related protein (TRP)-2 as a cytotoxic T lymphocyte target in patients with malignant glioma," Journal of Immunotherapy, vol. 26, no. 4, pp. 301-312, 2003.

[41] J. Wykosky, D. M. Gibo, C. Stanton, and W. Debinski, "Interleukin-13 receptor $\alpha 2$, EphA2, and Fos-related antigen 1 as molecular denominators of high-grade astrocytomas and specific targets for combinatorial therapy," Clinical Cancer Research, vol. 14, no. 1, pp. 199-208, 2008.

[42] M. Hatano, J. Eguchi, T. Tatsumi et al., "EphA2 as a gliomaassociated antigen: a novel target for glioma vaccines," Neoplasia, vol. 7, no. 8, pp. 717-722, 2005.

[43] M. Jin, Y. Komohara, S. Shichijo et al., "Identification of EphB6 variant-derived epitope peptides recognized by cytotoxic $\mathrm{T}$ lymphocytes from HLA-A24+ malignant glioma patients," Oncology Reports, vol. 19, no. 5, pp. 1277-1283, 2008.

[44] G. Liu, J. S. Yu, G. Zeng et al., "AIM-2: a novel tumor antigen is expressed and presented by human glioma cells," Journal of Immunotherapy, vol. 27, no. 3, pp. 220-226, 2004.

[45] M. Schmitz, R. Wehner, S. Stevanovic et al., "Identification of a naturally processed $\mathrm{T}$ cell epitope derived from the gliomaassociated protein SOX11," Cancer Letters, vol. 245, no. 1-2, pp. 331-336, 2007.

[46] H.-I. Cho, E.-K. Kim, S.-Y. Park, S. K. Lee, Y.-K. Hong, and T.-G. Kim, "Enhanced induction of anti-tumor immunity in human and mouse by dendritic cells pulsed with recombinant TAT fused human survivin protein," Cancer Letters, vol. 258, no. 2, pp. 189-198, 2007.

[47] T. Komata, T. Kanzawa, Y. Kondo, and S. Kondo, "Telomerase as a therapeutic target for malignant gliomas," Oncogene, vol. 21, no. 4, pp. 656-663, 2002.

[48] G. Z. Jian, J. Eguchi, C. A. Kruse et al., "Antigenic profiling of glioma cells to generate allogeneic vaccines or dendritic cellbased therapeutics," Clinical Cancer Research, vol. 13, no. 2, part 1, pp. 566-575, 2007.

[49] M. Harada, Y. Ishihara, K. Itoh, and R. Yamanaka, "Kinesin superfamily protein-derived peptides with the ability to induce glioma-reactive cytotoxic T lymphocytes in human leukocyte antigen-A24 + glioma patients," Oncology Reports, vol. 17, no. 3, pp. 629-636, 2007.

[50] M. S. Mahaley Jr., D. D. Bigner, L. F. Dudka et al., "Immunobiology of primary intracranial tumors. Part 7: active immunization of patients with anaplastic human glioma cells: a pilot study," Journal of Neurosurgery, vol. 59, no. 2, pp. 201-207, 1983.

[51] S. Kong, S. Sengupta, B. Tyler et al., "Suppression of human glioma xenografts with second-generation IL13R-specific chimeric antigen receptor-modified T cells," Clinical Cancer Research, vol. 18, no. 21, pp. 5949-5960, 2012.

[52] S. F. Hussain, D. Yang, D. Suki, K. Aldape, E. Grimm, and A. B. Heimberger, "The role of human glioma-infiltrating microglia/macrophages in mediating antitumor immune responses," Neuro-Oncology, vol. 8, no. 3, pp. 261-279, 2006.

[53] F. P. Holladay, "Autologous tumor cell vaccination combined with adoptive cellular immunotherapy in patients with grade III/IV astrocytoma," Journal of Neuro-Oncology, vol. 27, no. 2, pp. 179-189, 1996.

[54] M. Platten, A. Kretz, U. Naumann et al., "Monocyte chemoattractant protein-1 increases microglial infiltration and aggressiveness of gliomas," Annals of Neurology, vol. 54, no. 3, pp. 388392, 2003.

[55] M. Okada, M. Saio, Y. Kito et al., "Tumor-associated macrophage/microglia infiltration in human gliomas is correlated with MCP-3, but not MCP-1," International Journal of Oncology, vol. 34, no. 6, pp. 1621-1627, 2009.

[56] K. B. Quattrocchi, C. H. Miller, S. Cush et al., "Pilot study of local autologous tumor infiltrating lymphocytes for the treatment of recurrent malignant gliomas," Journal of NeuroOncology, vol. 45, no. 2, pp. 141-157, 1999.

[57] T. Kitahara, O. Watanabe, A. Yamaura et al., "Establishment of interleukin 2 dependent cytotoxic T lymphocyte cell line specific for autologous brain tumor and its intracranial administration for therapy of the tumor," Journal of Neuro-Oncology, vol. 4, no. 4, pp. 329-336, 1987.

[58] K. Tsuboi, K. Saijo, E. Ishikawa et al., "Effects of local injection of ex vivo expanded autologous tumor-specific T lymphocytes in cases with recurrent malignant gliomas," Clinical Cancer Research, vol. 9, no. 9, pp. 3294-3302, 2003.

[59] C. A. Kruse, L. Cepeda, B. Owens, S. D. Johnson, J. Stears, and K. O. Lillehei, "Treatment of recurrent glioma with intracavitary alloreactive cytotoxic T lymphocytes and interleukin-2," Cancer Immunology Immunotherapy, vol. 45, no. 2, pp. 77-87, 1997.

[60] R. O. Dillman, C. M. Duma, R. A. Ellis et al., "Intralesional lymphokine-activated killer cells as adjuvant therapy for primary glioblastoma," Journal of Immunotherapy, vol. 32, no. 9, pp. 914-919, 2009.

[61] R. O. Dillman, C. M. Duma, P. M. Schiltz et al., "Intracavitary placement of autologous lymphokine-activated killer (LAK) cells after resection of recurrent glioblastoma," Journal of Immunotherapy, vol. 27, no. 5, pp. 398-404, 2004.

[62] S. K. Sankhla, J. S. Nadkarni, and S. N. Bhagwati, "Adoptive immunotherapy using lymphokine-activated killer (LAK) cells and interleukin-2 for recurrent malignant primary brain tumors," Journal of Neuro-Oncology, vol. 27, no. 2, pp. 133-140, 1996.

[63] R. L. Hayes, M. Koslow, E. M. Hiesiger et al., "Improved long term survival after intracavitary interleukin-2 and lymphokineactivated killer cells for adults with recurrent malignant glioma," Cancer, vol. 76, no. 5, pp. 840-852, 1995.

[64] K. O. Lillehei, D. H. Mitchell, S. D. Johnson, E. L. McCleary, and C. A. Kruse, "Long-term follow-up of patients with recurrent malignant gliomas treated with adjuvant adoptive immunotherapy," Neurosurgery, vol. 28, no. 1, pp. 16-23, 1991.

[65] D. Barba, S. C. Saris, C. Holder, S. A. Rosenberg, and E. H. Oldfield, "Intratumoral LAK cell and interleukin-2 therapy of human gliomas," Journal of Neurosurgery, vol. 70, no. 2, pp. 175$182,1989$.

[66] R. E. Merchant, L. H. Merchant, S. H. S. Cook, D. W. McVicar, H. F. Young, and M. S. Mahaley Jr., "Intralesional infusion of lymphokine-activated killer (LAK) cells and recombinant Interleukin-2 (rIL-2) for the treatment of patients with malignant brain tumor," Neurosurgery, vol. 23, no. 6, pp. 725-732, 1988. 
[67] S. Yoshida, R. Tanaka, N. Takai, and K. Ono, "Local administration of autologous lymphokine-activated killer cells and recombinant interleukin 2 to patients with malignant brain tumors," Cancer Research, vol. 48, no. 17, pp. 5011-5016, 1988.

[68] R. E. Merchant, A. J. Grant, L. H. Merchant, and H. F. Young, "Adoptive immunotherapy for recurrent glioblastoma multiforme using lymphokine activated killer cells and recombinant interleukin-2," Cancer, vol. 62, no. 4, pp. 665-671, 1988.

[69] S. K. Jacobs, D. J. Wilson, P. L. Kornblith, and E. A. Grimm, "Interleukin-2 or autologous lymphokine-activated killer cell treatment of malignant glioma: phase I trial," Cancer Research, vol. 46, no. 4, part 2, pp. 2101-2104, 1986.

[70] A. Blancher, F. Roubinet, A. S. Grancher et al., "Local immunotherapy of recurrent glioblastoma multiforme by intracerebral perfusion of interleukin-2 and LAK cells," European Cytokine Network, vol. 4, no. 5, pp. 331-341, 1993.

[71] T. M. Law, R. J. Motzer, M. Mazumdar et al., "Phase III randomized trial of interleukin-2 with or without lymphokineactivated killer cells in the treatment of patients with advanced renal cell carcinoma," Cancer, vol. 76, no. 5, pp. 824-832, 1995.

[72] M. Bonneville and E. Scotet, "Human V $\gamma 9 \mathrm{~V} \delta 2 \mathrm{~T}$ cells: promising new leads for immunotherapy of infections and tumors," Current Opinion in Immunology, vol. 18, no. 5, pp. 539-546, 2006.

[73] H. Borghaei, M. R. Smith, and K. S. Campbell, "Immunotherapy of cancer," European Journal of Pharmacology, vol. 625, no. 1-3, pp. 41-54, 2009.

[74] S. Srivastava, A. Lundqvist, and R. W. Childs, "Natural killer cell immunotherapy for cancer: a new hope," Cytotherapy, vol. 10, no. 8, pp. 775-783, 2008.

[75] E. Vivier, E. Tomasello, M. Baratin, T. Walzer, and S. Ugolini, "Functions of natural killer cells," Nature Immunology, vol. 9, no. 5, pp. 503-510, 2008.

[76] R. Castriconi, A. Daga, A. Dondero et al., "NK cells recognize and kill human glioblastoma cells with stem cell-like properties," The Journal of Immunology, vol. 182, no. 6, pp. 3530-3539, 2009.

[77] D. Alizadeh, L. Zhang, C. E. Brown, O. Farrukh, M. C. Jensen, and B. Badie, "Induction of anti-glioma natural killer cell response following multiple low-dose intracerebral $\mathrm{CpG}$ therapy," Clinical Cancer Research, vol. 16, no. 13, pp. 3399-3408, 2010.

[78] E. Ishikawa, K. Tsuboi, S. Takano, E. Uchimura, T. Nose, and T. Ohno, "Intratumoral injection of IL-2-activated NK cells enhances the antitumor effect of intradermally injected paraformaldehyde-fixed tumor vaccine in a rat intracranial brain tumor model," Cancer Science, vol. 95, no. 1, pp. 98-103, 2004.

[79] P. Wang, J.-P. Yu, S.-Y. Gao et al., "Experimental study on the treatment of intracerebral glioma xenograft with human cytokine-induced killer cells," Cellular Immunology, vol. 253, no. 1-2, pp. 59-65, 2008.

[80] E. Ishikawa, K. Tsuboi, K. Saijo et al., "Autologous natural killer cell therapy for human recurrent malignant glioma," Anticancer Research, vol. 24, no. 3 B, pp. 1861-1871, 2004.

[81] S. Pellegatta, M. Eoli, S. Frigerio et al., "The natural killer cell response and tumor debulking are associated with prolonged survival in recurrent glioblastoma patients receiving dendritic cells loaded with autologous tumor lysates," Oncoimmunology, vol. 2, no. 3, Article ID e23401, 2013.

[82] L. Moretta, C. Bottino, D. Pende, R. Castriconi, M. C. Mingari, and A. Moretta, "Surface NK receptors and their ligands on tumor cells," Seminars in Immunology, vol. 18, no. 3, pp. 151-158, 2006.

[83] A. B. H. Bakker, J. H. Phillips, C. G. Figdor, and L. L. Lanier, "Killer cell inhibitory receptors for MHC class I molecules regulate lysis of melanoma cells mediated by NK cells, $\gamma \delta$ T cells, and antigen- specific CTL," The Journal of Immunology, vol. 160, no. 11, pp. 5239-5245, 1998.

[84] H. Fujisaki, H. Kakuda, N. Shimasaki et al., "Expansion of highly cytotoxic human natural killer cells for cancer cell therapy," Cancer Research, vol. 69, no. 9, pp. 4010-4017, 2009.

[85] M. Cheng, Y. Chen, W. Xiao, R. Sun, and Z. Tian, "NK cell-based immunotherapy for malignant diseases," Cellular and Molecular Immunology, vol. 10, no. 3, pp. 230-252, 2013.

[86] H. J. Pegram, M. H. Kershaw, and P. K. Darcy, "Genetic modification of natural killer cells for adoptive cellular immunotherapy," Immunotherapy, vol. 1, no. 4, pp. 623-630, 2009.

[87] S. Nagashima, R. Mailliard, Y. Kashii et al., "Stable transduction of the interleukin-2 gene into human natural killer cell lines and their phenotypic and functional characterization in vitro and in vivo," Blood, vol. 91, no. 10, pp. 3850-3861, 1998.

[88] S. R. Goding, Q. Yang, K. B. Knudsen, D. M. Potter, and P. H. Basse, "Cytokine gene therapy using adenovirally transduced, tumor-seeking activated natural killer cells," Human Gene Therapy, vol. 18, no. 8, pp. 701-711, 2007.

[89] N. L. Vujanovic, S. Yasumura, H. Hirabayashi et al., "Antitumor activities of subsets of human IL-2-activated natural killer cells in solid tissues," The Journal of Immunology, vol. 154, no. 1, pp. 281-289, 1995.

[90] J. S. Miller, J. Tessmer-Tuck, N. Blake et al., "Endogenous IL-2 production by natural killer cells maintains cytotoxic and proliferative capacity following retroviral-mediated gene transfer," Experimental Hematology, vol. 25, no. 11, pp. 1140$1148,1997$.

[91] J. Zhang, R. Sun, H. Wei, J. Zhang, and Z. Tian, "Characterization of interleukin-15 gene-modified human natural killer cells: implications for adoptive cellular immunotherapy," Haematologica, vol. 89, no. 3, pp. 338-347, 2004.

[92] C. Sahm, K. Schönfeld, and W. S. Wels, "Expression of IL-15 in NK cells results in rapid enrichment and selective cytotoxicity of gene-modiWed eVectors that carry a tumor-speciWc antigen receptor," Cancer Immunology, Immunotherapy, vol. 61, no. 9, pp. 1451-1461, 2012.

[93] W. Jiang, J. Zhang, and Z. Tian, "Functional characterization of interleukin-15 gene transduction into the human natural killer cell line NKL," Cytotherapy, vol. 10, no. 3, pp. 265-274, 2008.

[94] J. Zhang, R. Sun, H. Wei, J. Zhang, and Z. Tian, "Characterization of stem cell factor gene-modified human natural killer cell line, NK-92 cells: implication in NK cell-based adoptive cellular immunotherapy," Oncology Reports, vol. 11, no. 5, pp. 1097-1106, 2004.

[95] F. J. Demirtzoglou, S. Papadopoulos, and G. Zografos, "Cytolytic and cytotoxic activity of a human natural killer cell line genetically modified to specifically recognize HER2/neu overexpressing tumor cells," Immunopharmacology and Immunotoxicology, vol. 28, no. 4, pp. 571-590, 2006.

[96] T. Schirrmann and G. Pecher, "Human natural killer cell line modified with a chimeric immunoglobulin T-cell receptor gene leads to tumor growth inhibition in vivo," Cancer Gene Therapy, vol. 9, no. 4, pp. 390-398, 2002.

[97] T. Schirrmann and G. Pecher, "Specific targeting of CD33+ leukemia cells by a natural killer cell line modified with 
a chimeric receptor," Leukemia Research, vol. 29, no. 3, pp. 301306, 2005.

[98] V. Bronte, M. Wang, W. W. Overwijk et al., "Apoptotic death of CD8+ T lymphocytes after immunization: induction of a suppressive population of Mac-1+/Gr-1+ cells," The Journal of Immunology, vol. 161, no. 10, pp. 5313-5320, 1998.

[99] V. Bronte, E. Apolloni, A. Cabrelle et al., "Identification of a CD11b+/Gr-1+/CD31+ myeloid progenitor capable of activating or suppressing CD8+ T cells," Blood, vol. 96, no. 12, pp. 38383846, 2000.

[100] D. Lindau, P. Gielen, M. Kroesen, P. Wesseling, and G. J. Adema, "The immunosuppressive tumour network: myeloid-derived suppressor cells, regulatory T cells and natural killer T cells," Immunology, vol. 138, no. 2, pp. 105-115, 2013.

[101] B. Zhang, H. Jia, J. Liu et al., "Depletion of regulatory T cells facilitates growth of established tumors: a mechanism involving the regulation of myeloid-derived suppressor cells by lipoxin A4," The Journal of Immunology, vol. 185, no. 12, pp. 7199-7206, 2010.

[102] T. Fujimura, Y. Kambayashi, and S. Aiba, "Crosstalk between regulatory T cells (Tregs) and myeloid derived suppressor cells (MDSCs) during melanoma growth," Oncoimmunology, vol. 1, no. 8, pp. 1433-1434, 2012.

[103] B. Raychaudhuri, P. R. J. Ireland, J. Ko et al., "Myeloid-derived suppressor cell accumulation and function in patients with newly diagnosed glioblastoma," Neuro-Oncology, vol. 13, no. 6, pp. 591-599, 2011.

[104] J. C. Rodrigues, G. C. Gonzalez, L. Zhang et al., "Normal human monocytes exposed to glioma cells acquire myeloid-derived suppressor cell-like properties," Neuro-Oncology, vol. 12, no. 4, pp. 351-365, 2010.

[105] M. Fujita, G. Kohanbash, W. Fellows-Mayle et al., "COX2 blockade suppresses gliomagenesis by inhibiting myeloidderived suppressor cells," Cancer Research, vol. 71, no. 7, pp. 2664-2674, 2011.

[106] X. Zhu, M. Fujita, L. A. Snyder, and H. Okada, "Systemic delivery of neutralizing antibody targeting CCL2 for glioma therapy," Journal of Neuro-Oncology, vol. 104, no. 1, pp. 83-92, 2011.

[107] A. M. Sonabend, C. E. Rolle, and M. S. Lesniak, "The role of regulatory T cells in malignant glioma," Anticancer Research, vol. 28, no. 2, pp. 1143-1150, 2008.

[108] M. J. Smyth, M. W. L. Teng, J. Swann, K. Kyparissoudis, D. I. Godfrey, and Y. Hayakawa, "CD4+CD25+ T regulatory cells suppress NK cell-mediated immunotherapy of cancer," The Journal of Immunology, vol. 176, no. 3, pp. 1582-1587, 2006.

[109] H. Zhou, L. Chen, Y. You, L. Zou, and P. Zou, "Foxp3transduced polyclonal regulatory $\mathrm{T}$ cells suppress $\mathrm{NK}$ cell functions in a TGF- $\beta$ dependent manner," Autoimmunity, vol. 43, no. 4, pp. 299-307, 2010.

[110] L. S. Lamb Jr., " $\gamma \delta$ T cells as immune effectors against high-grade gliomas," Immunologic Research, vol. 45, no. 1, pp. 85-95, 2009.

[111] T. Yamaguchi, Y. Fujimiya, Y. Suzuki, R. Katakura, and T. Ebina, "A simple method for the propagation and purification of $\gamma \delta \mathrm{T}$ cells from the peripheral blood of glioblastoma patients using solid-phase anti-CD3 antibody and soluble IL-2," Journal of Immunological Methods, vol. 205, no. 1, pp. 19-28, 1997.

[112] Y. Fujimiya, Y. Suzuki, R. Katakura et al., "In vitro interleukin 12 activation of peripheral blood CD3+ CD56+ and CD3+ CD56$\gamma \delta$ T cells from glioblastoma patients," Clinical Cancer Research, vol. 3, no. 4, pp. 633-643, 1997.
[113] T. Yamaguchi, Y. Suzuki, R. Katakura, T. Ebina, J. Yokoyama, and Y. Fujimiya, "Interleukin-15 effectively potentiates the in vitro tumor-specific activity and proliferation of peripheral blood $\gamma \delta$ T cells isolated from glioblastoma patients," Cancer Immunology Immunotherapy, vol. 47, no. 2, pp. 97-103, 1998.

[114] N. L. Bryant, G. Y. Gillespie, R. D. Lopez et al., "Preclinical evaluation of ex vivo expanded/activated $\gamma \delta \mathrm{T}$ cells for immunotherapy of glioblastoma multiforme," Journal of NeuroOncology, vol. 101, no. 2, pp. 179-188, 2011.

[115] N. L. Bryant, C. Suarez-Cuervo, G. Y. Gillespie et al., "Characterization and immunotherapeutic potential of $\gamma \delta$ T-cells in patients with glioblastoma," Neuro-Oncology, vol. 11, no. 4, pp. 357-367, 2009.

[116] L. S. Lamb Jr., J. Bowersock, A. Dasgupta et al., "Engineered drug resistant $\gamma \delta \mathrm{T}$ cells kill glioblastoma cell lines during a chemotherapy challenge: a strategy for combining chemo- and immunotherapy," PLoS ONE, vol. 8, no. 1, Article ID e51805, 2013.

[117] P. M. Schlitz, L. D. Beutel, S. K. Nayak, and R. O. Dillman, "Characterization of tumor-infiltrating lymphocytes derived from human tumors for use as adoptive immunotherapy of cancer," Journal of Immunotherapy, vol. 20, no. 5, pp. 377-386, 1997.

[118] M. E. Dudley, J. R. Wunderlich, P. F. Robbins et al., "Cancer regression and autoimmunity in patients after clonal repopulation with antitumor lymphocytes," Science, vol. 298, no. 5594, pp. 850-854, 2002.

[119] M. E. Dudley, J. C. Yang, R. Sherry et al., "Adoptive cell therapy for patients with metastatic melanoma: evaluation of intensive myeloablative chemoradiation preparative regimens," Journal of Clinical Oncology, vol. 26, no. 32, pp. 5233-5239, 2008.

[120] C. M. Balch, L. B. Riley, Y. J. Bae et al., "Patterns of human tumor-infiltrating lymphocytes in 120 human cancers," Archives of Surgery, vol. 125, no. 2, pp. 200-205, 1990.

[121] H. Tsurushima, S. Q. Liu, K. Tuboi et al., "Reduction of endstage malignant glioma by injection with autologous cytotoxic T lymphocytes," Japanese Journal of Cancer Research, vol. 90, no. 5, pp. 536-545, 1999.

[122] G. E. Plautz, D. W. Miller, G. H. Barnett et al., "T cell adoptive immunotherapy of newly diagnosed gliomas," Clinical Cancer Research, vol. 6, no. 6, pp. 2209-2218, 2000.

[123] G. E. Plautz, G. H. Barnett, D. W. Miller et al., "Systemic T cell adoptive immunotherapy of malignant gliomas," Journal of Neurosurgery, vol. 89, no. 1, pp. 42-51, 1998.

[124] G. W. Wood, F. P. Holladay, T. Turner, Y.-Y. Wang, and M. Chiga, "A pilot study of autologous cancer cell vaccination and cellular immunotherapy using anti-CD3 stimulated lymphocytes in patients with recurrent grade III/IV astrocytoma," Journal of Neuro-Oncology, vol. 48, no. 2, pp. 113-120, 2000.

[125] A. E. Sloan, R. Dansey, L. Zamorano et al., "Adoptive immunotherapy in patients with recurrent malignant glioma: preliminary results of using autologous whole-tumor vaccine plus granulocyte-macrophage colony-stimulating factor and adoptive transfer of anti-CD3-activated lymphocytes," Neurosurgical Focus, vol. 9, no. 6, p. e9, 2000.

[126] S. Ostrand-Rosenberg, "CD4+ T lymphocytes: a critical component of antitumor immunity," Cancer Investigation, vol. 23, no. 5, pp. 413-419, 2005.

[127] D. M. Pardoll and S. L. Topalian, "The role of CD4+ T cell responses in antitumor immunity," Current Opinion in Immunology, vol. 10, no. 5, pp. 588-594, 1998. 
[128] N. N. Hunder, H. Wallen, J. Cao et al., "Treatment of metastatic melanoma with autologous CD4+ T cells against NY-ESO-1," The New England Journal of Medicine, vol. 358, no. 25, pp. 26982703, 2008.

[129] F. R. Depontieu, J. Qian, A. L. Zarling et al., "Identification of tumor-associated, MHC class II-restricted phosphopeptides as targets for immunotherapy," Proceedings of the National Academy of Sciences of the United States of America, vol. 106, no. 29, pp. 12073-12078, 2009.

[130] A. Perez-Diez, N. T. Joncker, K. Choi et al., "CD4 cells can be more efficient at tumor rejection than CD8 cells," Blood, vol. 109, no. 12, pp. 5346-5354, 2007.

[131] F. Ossendorp, E. Mengedé, M. Camps, R. Filius, and C. J. M. Melief, "Specific T helper cell requirement for optimal induction of cytotoxic T lymphocytes against major histocompatibility complex class II negative tumors," The Journal of Experimental Medicine, vol. 187, no. 5, pp. 693-702, 1998.

[132] Y. Xie, A. Akpinarli, C. Maris et al., "Naive tumor-specific CD4+ T cells differentiated in vivo eradicate established melanoma," The Journal of Experimental Medicine, vol. 207, no. 3, pp. 651667, 2010

[133] S. A. Quezada, T. R. Simpson, K. S. Peggs et al., "Tumor-reactive CD4+ T cells develop cytotoxic activity and eradicate large established melanoma after transfer into lymphopenic hosts," The Journal of Experimental Medicine, vol. 207, no. 3, pp. 637650, 2010.

[134] J. Xiang and T. Moyana, "Cytotoxic CD4+ T cells associated with the expression of major histocompatibility complex class II antigen of mouse myeloma cells secreting interferon- $\gamma$ are cytolytic in vitro and tumoricidal in vivo," Cancer Gene Therapy, vol. 5, no. 5, pp. 313-320, 1998.

[135] F. S. Hodi and D. E. Fisher, "Adoptive transfer of antigen-specific CD4+ T cells in the treatment of metastatic melanoma," Nature Clinical Practice Oncology, vol. 5, no. 12, pp. 696-697, 2008.

[136] Z. Dembic, W. Haas, S. Weiss et al., "Transfer of specificity by murine $\alpha$ and $\beta$ T-cell receptor genes," Nature, vol. 320, no. 6059, pp. 232-238, 1986.

[137] M. T. Stephan, V. Ponomarev, R. J. Brentjens et al., “T cellencoded CD80 and 4-1BBL induce auto- and transcostimulation, resulting in potent tumor rejection," Nature Medicine, vol. 13, no. 12, pp. 1440-1449, 2007.

[138] K. Liu and S. A. Rosenberg, "Transduction of an IL-2 gene into human melanoma-reactive lymphocytes results in their continued growth in the absence of exogenous IL-2 and maintenance of specific antitumor activity," The Journal of Immunology, vol. 167, no. 11, pp. 6356-6365, 2001.

[139] C. Hsu, M. S. Hughes, Z. Zheng, R. B. Bray, S. A. Rosenberg, and R. A. Morgan, "Primary human T lymphocytes engineered with a codon-optimized IL-15 gene resist cytokine withdrawalinduced apoptosis and persist long-term in the absence of exogenous cytokine," The Journal of Immunology, vol. 175, no. 11, pp. 7226-7234, 2005.

[140] J. F. Vera, V. Hoyos, B. Savoldo et al., "Genetic manipulation of tumor-specific cytotoxic T lymphocytes to restore responsiveness to IL-7," Molecular Therapy, vol. 17, no. 5, pp. 880-888, 2009.

[141] S. P. Kerkar, P. Muranski, A. Kaiser et al., “Tumor-specific CD8+ $\mathrm{T}$ cells expressing interleukin-12 eradicate established cancers in lymphodepleted hosts," Cancer Research, vol. 70, no. 17, pp. 6725-6734, 2010

[142] A. Kalbasi, R. K. Shrimali, D. Chinnasamy, and S. A. Rosenberg, "Prevention of interleukin-2 withdrawal-induced apoptosis in lymphocytes retrovirally cotransduced with genes encoding an antitumor t-cell receptor and an antiapoptotic protein," Journal of Immunotherapy, vol. 33, no. 7, pp. 672-683, 2010.

[143] D. Eaton, D. E. Gilham, A. O'Neill, and R. E. Hawkins, "Retroviral transduction of human peripheral blood lymphocytes with bcl-XL promotes in vitro lymphocyte survival in pro-apoptotic conditions," Gene Therapy, vol. 9, no. 8, pp. 527-535, 2002.

[144] J. Charo, S. E. Finkelstein, N. Grewal, N. P. Restifo, P. F. Robbins, and S. A. Rosenberg, "Bcl-2 overexpression enhances tumorspecific T-cell survival," Cancer Research, vol. 65, no. 5, pp. 20012008, 2005.

[145] E. Mizukoshi, Y. Nakamoto, Y. Marukawa et al., "Cytotoxic T cell responses to human telomerase reverse transcriptase in patients with hepatocellular carcinoma," Hepatology, vol. 43, no. 6, pp. 1284-1294, 2006.

[146] X. Shen, J. Zhou, K. S. Hathcock et al., "Persistence of tumor infiltrating lymphocytes in adoptive immunotherapy correlates with telomere length," Journal of Immunotherapy, vol. 30, no. 1, pp. 123-129, 2007.

[147] M. Migliaccio, M. Amacker, T. Just et al., "Ectopic human telomerase catalytic subunit expression maintains telomere length but is not sufficient for CD8+ T lymphocyte immortalization," The Journal of Immunology, vol. 165, no. 9, pp. 4978-4984, 2000.

[148] E. Hooijberg, J. J. Ruizendaal, P. J. F. Snijders, E. W. M. Kueter, J. M. M. Walboomers, and H. Spits, "Immortalization of human CD8+ T cell clones by ectopic expression of telomerase reverse transcriptase," The Journal of Immunology, vol. 165, no. 8, pp. 4239-4245, 2000.

[149] S. Sapoznik, R. Ortenberg, G. Galore-Haskel et al., "CXCR1 as a novel target for directing reactive $\mathrm{T}$ cells toward melanoma: implications for adoptive cell transfer immunotherapy," Cancer Immunology, Immunotherapy, vol. 61, no. 10, pp. 1833-1847, 2012.

[150] W. Peng, Y. Ye, B. A. Rabinovich et al., “Transduction of tumorspecific $\mathrm{T}$ cells with CXCR2 chemokine receptor improves migration to tumor and antitumor immune responses," Clinical Cancer Research, vol. 16, no. 22, pp. 5458-5468, 2010.

[151] J. A. Craddock, A. Lu, A. Bear et al., "Enhanced tumor trafficking of GD2 chimeric antigen receptor T cells by expression of the chemokine receptor CCR2b," Journal of Immunotherapy, vol. 33, no. 8, pp. 780-788, 2010.

[152] M. H. Kershaw, P. Hwu, G. Wang et al., "Redirecting migration of $\mathrm{T}$ cells to chemokine secreted from tumors by genetic modification with CXCR2," Human Gene Therapy, vol. 13, no. 16, pp. 1971-1980, 2002.

[153] L. Wang, W. Wen, J. Yuan et al., "Immunotherapy for human renal cell carcinoma by adoptive transfer of autologous transforming growth factor $\beta$-insensitive CD8+ T cells," Clinical Cancer Research, vol. 16, no. 1, pp. 164-173, 2010.

[154] Q. Zhang, X. Yang, M. Pins et al., "Adoptive transfer of tumorreactive transforming growth factor- $\beta$-insensitive $\mathrm{CD} 8+\mathrm{T}$ cells: eradication of autologous mouse prostate cancer," Cancer Research, vol. 65, no. 5, pp. 1761-1769, 2005.

[155] C. M. Bollard, C. Rössig, M. Julia Calonge et al., "Adapting a transforming growth factor $\beta$-related tumor protection strategy to enhance antitumor immunity," Blood, vol. 99, no. 9, pp. 3179$3187,2002$.

[156] A. E. Foster, G. Dotti, A. Lu et al., "Antitumor activity of EBVspecific T lymphocytes transduced with a dominant negative TGF- $\beta$ receptor," Journal of Immunotherapy, vol. 31, no. 5, pp. 500-505, 2008. 
[157] G. Dotti, B. Savoldo, M. Pule et al., "Human cytotoxic T lymphocytes with reduced sensitivity to Fas-induced apoptosis," Blood, vol. 105, no. 12, pp. 4677-4684, 2005.

[158] N. P. Restifo, M. E. Dudley, and S. A. Rosenberg, "Adoptive immunotherapy for cancer: harnessing the T cell response," Nature Reviews Immunology, vol. 12, no. 4, pp. 269-281, 2012.

[159] N. M. Haynes, J. A. Trapani, M. W. L. Teng et al., "Rejection of syngeneic colon carcinoma by CTLs expressing singlechain antibody receptors codelivering CD28 costimulation," The Journal of Immunology, vol. 169, no. 10, pp. 5780-5786, 2002.

[160] C.-J. Shen, Y.-X. Yang, E. Q. Han et al., "Chimeric antigen receptor containing ICOS signaling domain mediates specific and efficient antitumor effect of $\mathrm{T}$ cells against EGFRvIII expressing glioma," Journal of Hematology and Oncology, vol. 6, no. 1 , article 33, 2013.

[161] K. G. Lucas, L. Bao, R. Bruggeman, K. Dunham, and C. Specht, "The detection of CMV pp65 and IE1 in glioblastoma multiforme," Journal of Neuro-Oncology, vol. 103, no. 2, pp. 231238, 2011.

[162] K. Dziurzynski, J. Wei, W. Qiao et al., "Glioma-associated cytomegalovirus mediates subversion of the monocyte lineage to a tumor propagating phenotype," Clinical Cancer Research, vol. 17, no. 14, pp. 4642-4649, 2011.

[163] A. Ghazi, A. Ashoori, P. J. Hanley et al., "Generation of polyclonal CMV-specific T cells for the adoptive immunotherapy of glioblastoma," Journal of Immunotherapy, vol. 35, no. 2, pp. 159$168,2012$.

[164] T. Crough, L. Beagley, C. Smith, L. Jones, D. G. Walker, and R. Khanna, "Ex vivo functional analysis, expansion and adoptive transfer of cytomegalovirus-specific T-cells in patients with glioblastoma multiforme," Immunology and Cell Biology, vol. 90, no. 9, pp. 872-880, 2012.

[165] C. E. Brown, R. Starr, A. Naranjo et al., "Adoptive transfer of autologous IL13-zetakine+ engineered T cell clones for the treatment of recurrent glioblastoma: lessons from the Clinic," Molecular Therapy, vol. 19, supplement 1, pp. S136-S137, 2011.

[166] J. H. Sampson, A. B. Heimberger, G. E. Archer et al., "Immunologic escape after prolonged progression-free survival with epidermal growth factor receptor variant III peptide vaccination in patients with newly diagnosed glioblastoma," Journal of Clinical Oncology, vol. 28, no. 31, pp. 4722-4729, 2010.

[167] R. A. Morgan, J. C. Yang, M. Kitano, M. E. Dudley, C. M. Laurencot, and S. A. Rosenberg, "Case report of a serious adverse event following the administration of $\mathrm{T}$ cells transduced with a chimeric antigen receptor recognizing ERBB2," Molecular Therapy, vol. 18, no. 4, pp. 843-851, 2010.

[168] Y. Zhang, G. Joe, E. Hexner, J. Zhu, and S. G. Emerson, "Hostreactive $\mathrm{CD} 8+$ memory stem cells in graft-versus-host disease," Nature Medicine, vol. 11, no. 12, pp. 1299-1305, 2005.

[169] C. A. Klebanoff, L. Gattinoni, and N. P. Restifo, "Sorting through subsets: which T-cell populations mediate highly effective adoptive immunotherapy?" Journal of Immunotherapy, vol. 35, no. 9, pp. 651-660, 2012.

[170] C. S. Hinrichs, R. Spolski, C. M. Paulos et al., "IL-2 and IL-21 confer opposing differentiation programs to CD8+ T cells for adoptive immunotherapy," Blood, vol. 111, no. 11, pp. 5326-5333, 2008.

[171] Y. Li, M. Bleakley, and C. Yee, "IL-21 influences the frequency, phenotype, and affinity of the antigen-specific CD8 T cell response," The Journal of Immunology, vol. 175, no. 4, pp. 2261$2269,2005$.
[172] N. Pouw, E. Treffers-Westerlaken, A. Mondino, C. Lamers, and R. Debets, "TCR gene-engineered T cell: limited T cell activation and combined use of IL-15 and IL-21 ensure minimal differentiation and maximal antigen-specificity," Molecular Immunology, vol. 47, no. 7-8, pp. 1411-1420, 2010.

[173] L. Gattinoni, X.-S. Zhong, D. C. Palmer et al., "Wnt signaling arrests effector $\mathrm{T}$ cell differentiation and generates CD8 + memory stem cells," Nature Medicine, vol. 15, no. 7, pp. 808-813, 2009.

[174] S. Muralidharan, P. J. Hanley, E. Liu et al., "Activation of Wnt signaling arrests effector differentiation in human peripheral and cord blood-derived T lymphocytes," The Journal of Immunology, vol. 187, no. 10, pp. 5221-5232, 2011.

[175] E. Lugli, M. H. Dominguez, L. Gattinoni et al., "Superior $\mathrm{T}$ memory stem cell persistence supports long-lived $\mathrm{T}$ cell memory," The Journal of Clinical Investigation, vol. 123, no. 2, pp. 594-599, 2013.

[176] C. A. Klebanoff, L. Gattinoni, P. Torabi-Parizi et al., "Central memory self/tumor-reactive CD8+ $\mathrm{T}$ cells confer superior antitumor immunity compared with effector memory T cells," Proceedings of the National Academy of Sciences of the United States of America, vol. 102, no. 27, pp. 9571-9576, 2005.

[177] L. Gattinoni, E. Lugli, Y. Ji et al., "A human memory T cell subset with stem cell-like properties," Nature Medicine, vol. 17, no. 10, pp. 1290-1297, 2011.

[178] C. Tanchot, M. M. Rosado, F. Agenes, A. A. Freitas, and B. Rocha, "Lymphocyte homeostasis," Seminars in Immunology, vol. 9, no. 6, pp. 331-337, 1997.

[179] M. Cobbold, N. Khan, B. Pourgheysari et al., "Adoptive transfer of cytomegalovirus-specific CTL to stem cell transplant patients after selection by HLA-peptide tetramers," The Journal of Experimental Medicine, vol. 202, no. 3, pp. 379-386, 2005.

[180] B. K. Cho, V. P. Rao, Q. Ge, H. N. Eisen, and J. Chen, "Homeostasis-stimulated proliferation drives naive $\mathrm{T}$ cells to differentiate directly into memory $\mathrm{T}$ cells," The Journal of Experimental Medicine, vol. 192, no. 4, pp. 549-556, 2000.

[181] W. Dummer, A. G. Niethammer, R. Baccala et al., "T cell homeostatic proliferation elicits effective antitumor autoimmunity," The Journal of Clinical Investigation, vol. 110, no. 2, pp. 185-192, 2002.

[182] W. Asavaroengchai, Y. Kotera, and J. J. Mulé, “Tumor lysatepulsed dendritic cells can elicit an effective antitumor immune response during early lymphoid recovery," Proceedings of the National Academy of Sciences of the United States of America, vol. 99, no. 2, pp. 931-936, 2002.

[183] H.-M. Hu, C. H. Poehlein, W. J. Urba, and B. A. Fox, "Development of antitumor immune responses in reconstituted lymphopenic hosts," Cancer Research, vol. 62, no. 14, pp. 39143919, 2002.

[184] N. Koike, S. Pilon-Thomas, and J. J. Mulé, "Nonmyeloablative chemotherapy followed by T-cell adoptive transfer and dendritic cell-based vaccination results in rejection of established melanoma," Journal of Immunotherapy, vol. 31, no. 4, pp. 402412, 2008.

[185] J. J. Hong, S. A. Rosenberg, M. E. Dudley et al., "Successful treatment of melanoma brain metastases with adoptive cell therapy," Clinical Cancer Research, vol. 16, no. 19, pp. 4892-4898, 2010.

[186] S. A. Rosenberg and M. E. Dudley, "Cancer regression in patients with metastatic melanoma after the transfer of autologous antitumor lymphocytes," Proceedings of the National 
Academy of Sciences of the United States of America, vol. 101, supplement 2, pp. 14639-14645, 2004.

[187] C. King, A. Ilic, K. Koelsch, and N. Sarvetnick, "Homeostatic expansion of $\mathrm{T}$ cells during immune insufficiency generates autoimmunity," Cell, vol. 117, no. 2, pp. 265-277, 2004.

[188] T. Krupica Jr., T. J. Fry, and C. L. Mackall, "Autoimmunity during lymphopenia: a two-hit model," Clinical Immunology, vol. 120, no. 2, pp. 121-128, 2006.

[189] D. J. Powell Jr., M. E. Dudley, K. A. Hogan, J. R. Wunderlich, and S. A. Rosenberg, "Adoptive transfer of vaccineinduced peripheral blood mononuclear cells to patients with metastatic melanoma following lymphodepletion," The Journal of Immunology, vol. 177, no. 9, pp. 6527-6539, 2006.

[190] L. Christiansson, S. Söderlund, E. Svensson et al., "Increased Level of Myeloid-Derived Suppressor Cells, Programmed Death Receptor Ligand 1/Programmed Death Receptor 1, and Soluble CD25 in Sokal High Risk Chronic Myeloid Leukemia," PLoS ONE, vol. 8, no. 1, Article ID e55818, 2013.

[191] L. Wang, E. W. Y. Chang, S. Wong, S.-M. Ong, D. Q. Y. Chong, and K. L. Ling, "Increased myeloid-derived suppressor cells in gastric cancer correlate with cancer stage and plasma S100A8/A9 proinflammatory proteins," The Journal of Immunology, vol. 190, no. 2, pp. 794-804, 2013.

[192] S. Ohki, M. Shibata, K. Gonda et al., "Circulating myeloidderived suppressor cells are increased and correlate to immune suppression, inflammation and hypoproteinemia in patients with cancer," Oncology Reports, vol. 28, no. 2, pp. 453-458, 2012.

[193] D. I. Gabrilovich and S. Nagaraj, "Myeloid-derived suppressor cells as regulators of the immune system," Nature Reviews Immunology, vol. 9, no. 3, pp. 162-174, 2009.

[194] K. N. Kodumudi, A. Weber, A. A. Sarnaik, and S. Pilon-Thomas, "Blockade of myeloid-derived suppressor cells after induction of lymphopenia improves adoptive $\mathrm{T}$ cell therapy in a murine model of melanoma," The Journal of Immunology, vol. 189, no. 11, pp. 5147-5154, 2012.

[195] C. J. Winstead, J. M. Fraser, and A. Khoruts, "Regulatory CD4 $+\mathrm{CD} 25+$ Foxp $3+\mathrm{T}$ cells selectively inhibit the spontaneous form of lymphopenia-induced proliferation of naive T cells," The Journal of Immunology, vol. 180, no. 11, pp. 7305-7317, 2008.

[196] C. J. Winstead, C. S. Reilly, J. J. Moon et al., "CD4+CD25+Foxp3+ regulatory $\mathrm{T}$ cells optimize diversity of the conventional $\mathrm{T}$ cell repertoire during reconstitution from lymphopenia," The Journal of Immunology, vol. 184, no. 9, pp. 4749-4760, 2010.

[197] J. Baba, S. Watanabe, Y. Saida et al., "Depletion of radio-resistant regulatory $\mathrm{T}$ cells enhances antitumor immunity during recovery from lymphopenia," Blood, vol. 120, no. 12, pp. 2417-2427, 2012.

[198] J. H. Sampson, R. J. Schmittling, G. E. Archer et al., "A pilot study of IL-2R $\alpha$ blockade during lymphopenia depletes regulatory Tcells and correlates with enhanced immunity in patients with glioblastoma," PLoS ONE, vol. 7, no. 2, Article ID e31046, 2012.

[199] C. Wrzesinski, C. M. Paulos, L. Gattinoni et al., "Hematopoietic stem cells promote the expansion and function of adoptively transferred antitumor CD8+ T cells," The Journal of Clinical Investigation, vol. 117, no. 2, pp. 492-501, 2007.

[200] C. M. Paulos, C. Wrzesinski, A. Kaiser et al., "Microbial translocation augments the function of adoptively transferred self/tumor-specific CD8+ T cells via TLR4 signaling," The Journal of Clinical Investigation, vol. 117, no. 8, pp. 2197-2204, 2007.
[201] A. Wallace, V. Kapoor, J. Sun et al., "Transforming growth factor- $\beta$ receptor blockade augments the effectiveness of adoptive T-cell therapy of established solid cancers," Clinical Cancer Research, vol. 14, no. 12, pp. 3966-3974, 2008.

[202] D. H. Wong'S, "Inhibiting TGF- $\beta$ signaling restores immune surveillance in the SMA-560 glioma model," Neuro-Oncology, vol. 9, no. 3, pp. 259-270, 2007.

[203] M. Uhl, S. Aulwurm, J. Wischhusen et al., "SD-208, a novel transforming growth factor $\beta$ receptor I kinase inhibitor, inhibits growth and invasiveness and enhances immunogenicity of murine and human glioma cells in vitro and in vivo," Cancer Research, vol. 64, no. 21, pp. 7954-7961, 2004.

[204] P. Hau, P. Jachimczak, and U. Bogdahn, "Treatment of malignant gliomas with TGF- $\beta 2$ antisense oligonucleotides," Expert Review of Anticancer Therapy, vol. 9, no. 11, pp. 1663-1674, 2009.

[205] U. Bogdahn, P. Hau, G. Stockhammer et al., "Targeted therapy for high-grade glioma with the TGF- $\beta 2$ inhibitor trabedersen: results of a randomized and controlled phase IIb study," NeuroOncology, vol. 13, no. 1, pp. 132-142, 2011.

[206] C. B. Schmidt-Weber and K. Blaser, "Regulation and role of transforming growth factor- $\beta$ in immune tolerance induction and inflammation," Current Opinion in Immunology, vol. 16, no. 6, pp. 709-716, 2004.

[207] U. Petrausch, S. M. Jensen, C. Twitty et al., "Disruption of TGF$\beta$ signaling prevents the generation of tumor-sensitized regulatory T cells and facilitates therapeutic antitumor immunity," The Journal of Immunology, vol. 183, no. 6, pp. 3682-3689, 2009.

[208] P. E. Fecci, D. A. Mitchell, J. F. Whitesides et al., "Increased regulatory T-cell fraction amidst a diminished CD4 compartment explains cellular immune defects in patients with malignant glioma," Cancer Research, vol. 66, no. 6, pp. 3294-3302, 2006.

[209] D. A. Randolph and C. G. Fathman, "CD4+CD25+ regulatory $\mathrm{T}$ cells and their therapeutic potential," Annual Review of Medicine, vol. 57, pp. 381-402, 2006.

[210] W. Humphries, J. Wei, J. H. Sampson, and A. B. Heimberger, "The role of tregs in glioma-mediated immunosuppression: potential target for intervention," Neurosurgery Clinics of North America, vol. 21, no. 1, pp. 125-137, 2010.

[211] D. J. Powell Jr., A. Felipe-Silva, M. J. Merino et al., "Administration of a CD25-directed immunotoxin, LMB-2, to patients with metastatic melanoma induces a selective partial reduction in regulatory T cells in vivo," The Journal of Immunology, vol. 179, no. 7, pp. 4919-4928, 2007.

[212] D. A. Mitchell, X. Cui, R. J. Schmittling et al., "Monoclonal antibody blockade of IL-2 receptor $\alpha$ during lymphopenia selectively depletes regulatory $\mathrm{T}$ cells in mice and humans," Blood, vol. 118, no. 11, pp. 3003-3012, 2011.

[213] P. E. Fecci, H. Ochiai, D. A. Mitchell et al., "Systemic CTLA-4 blockade ameliorates glioma-induced changes to the CD4+ T cell compartment without affecting regulatory T-cell function," Clinical Cancer Research, vol. 13, no. 7, pp. 2158-2167, 2007.

[214] P. Agarwalla, Z. Barnard, P. Fecci, G. Dranoff, and W. T. Curry, "Sequential immunotherapy by vaccination with GMCSF-expressing glioma cells and CTLA-4 blockade effectively treats established murine intracranial tumors," Journal of Immunotherapy, vol. 35, no. 5, pp. 385-389, 2012.

[215] R. Bedel, A. Thiery-Vuillemin, C. Grandclement et al., "Novel role for STAT3 in transcriptional regulation of NK immune cell targeting receptor MICA on cancer cells," Cancer Research, vol. 71, no. 5, pp. 1615-1626, 2011.

[216] M. Fujita, X. Zhu, K. Sasaki et al., "Inhibition of STAT3 promotes the efficacy of adoptive transfer therapy using type-1 
CTLs by modulation of the immunological microenvironment in a murine intracranial glioma," The Journal of Immunology, vol. 180, no. 4, pp. 2089-2098, 2008.

[217] S. F. Hussain, L.-Y. Kong, J. Jordan et al., "A novel small molecule inhibitor of signal transducers and activators of transcription 3 reverses immune tolerance in malignant glioma patients," Cancer Research, vol. 67, no. 20, pp. 9630-9636, 2007.

[218] J. Wei, F. Wang, L.-Y. Kong et al., "MiR-124 inhibits STAT3 signaling to enhance $\mathrm{T}$ cell-mediated immune clearance of glioma," Cancer Research, vol. 73, no. 13, pp. 3913-3926, 2013.

[219] C. Banissi, F. Ghiringhelli, L. Chen, and A. F. Carpentier, "Treg depletion with a low-dose metronomic temozolomide regimen in a rat glioma model," Cancer Immunology, Immunotherapy, vol. 58, no. 10, pp. 1627-1634, 2009.

[220] J. T. Jordan, W. Sun, S. F. Hussain, G. DeAngulo, S. S. Prabhu, and A. B. Heimberger, "Preferential migration of regulatory T cells mediated by glioma-secreted chemokines can be blocked with chemotherapy," Cancer Immunology, Immunotherapy, vol. 57, no. 1, pp. 123-131, 2008.

[221] F. Hirata, S. Nomiyama, and O. Hayaishi, "Indoleamine 2,3 dioxygenase. Note I. Catalytic and molecular properties," Acta Vitaminologica et Enzymologica, vol. 29, no. 1-6, pp. 288-290, 1975.

[222] O. Hayaishi, F. Hirata, M. Fujiwara, S. Senoh, and T. Tokuyama, "Indoleamine 2,3 dioxygenase. Note II. Biological function," Acta Vitaminologica et Enzymologica, vol. 29, no. 1-6, pp. 291293, 1975.

[223] C. Uyttenhove, L. Pilotte, I. Théate et al., "Evidence for a tumoral immune resistance mechanism based on tryptophan degradation by indoleamine 2,3-dioxygenase," Nature Medicine, vol. 9, no. 10, pp. 1269-1274, 2003.

[224] M. Friberg, R. Jennings, M. Alsarraj et al., "Indoleamine 2,3-dioxygenase contributes to tumor cell evasion of $\mathrm{T}$ cellmediated rejection," International Journal of Cancer, vol. 101, no. 2, pp. 151-155, 2002.

[225] P. Hwu, M. X. Du, R. Lapointe, M. Do, M. W. Taylor, and H. A. Young, "Indoleamine 2,3-dioxygenase production by human dendritic cells results in the inhibition of T cell proliferation," The Journal of Immunology, vol. 164, no. 7, pp. 3596-3599, 2000.

[226] D. J. Chung, M. Rossi, E. Romano et al., "Indoleamine 2,3dioxygenase-expressing mature human monocyte-derived dendritic cells expand potent autologous regulatory T cells," Blood, vol. 114, no. 3, pp. 555-563, 2009.

[227] X. Liu, N. Shin, H. K. Koblish et al., "Selective inhibition of IDO1 effectively regulates mediators of antitumor immunity," Blood, vol. 115, no. 17, pp. 3520-3530, 2010.

[228] M. Sioud, S. Sæbøe-Larssen, T. E. Hetland, J. Kærn, A. Mobergslien, and G. Kvalheim, "Silencing of indoleamine 2,3dioxygenaseenhances dendritic cell immunogenicity and antitumour immunity in cancer patients," International Journal of Oncology, vol. 43, no. 1, pp. 280-288, 2013.

[229] R. B. Sørensen, S. R. Hadrup, I. M. Svane, M. C. Hjortsø, P. T. Straten, and M. H. Andersen, "Indoleamine 2,3-dioxygenase specific, cytotoxic T cells as immune regulators," Blood, vol. 117, no. 7, pp. 2200-2210, 2011.

[230] V. P. Balachandran, M. J. Cavnar, S. Zeng et al., "Imatinib potentiates antitumor $\mathrm{T}$ cell responses in gastrointestinal stromal tumor through the inhibition of Ido," Nature Medicine, vol. 17, no. 9, pp. 1094-1100, 2011.

[231] T. Miyazaki, K. Moritake, K. Yamada et al., "Indoleamine 2,3dioxygenase as a new target for malignant glioma therapy: laboratory investigation," Journal of Neurosurgery, vol. 111, no. 2, pp. 230-237, 2009.

[232] K. Mitsuka, T. Kawataki, E. Satoh, T. Asahara, T. Horikoshi, and H. Kinouchi, "Expression of indoleamine 2,3-dioxygenase and correlation with pathological malignancy in gliomas," Neurosurgery, vol. 72, no. 6, pp. 1031-1039, 2013.

[233] D. A. Wainwright, I. V. Balyasnikova, A. L. Chang et al., "IDO expression in brain tumors increases the recruitment of regulatory T cells and negatively impacts survival," Clinical Cancer Research, vol. 18, no. 22, pp. 6110-6121, 2012.

[234] B. D. Choi, P. E. Fecci, and J. H. Sampson, "Regulatory T cells move in when gliomas say "I DO',' Clinical Cancer Research, vol. 18, no. 22, pp. 6086-6088, 2012.

[235] S. R. Mattarollo, T. Kenna, M. Nieda, and A. J. Nicol, "Chemotherapy pretreatment sensitizes solid tumor-derived cell lines to V $\alpha 24+$ NKT cell-mediated cytotoxicity," International Journal of Cancer, vol. 119, no. 7, pp. 1630-1637, 2006.

[236] L. Aymeric, L. Apetoh, F. Ghiringhelli et al., "Tumor cell death and ATP release prime dendritic cells and efficient anticancer immunity," Cancer Research, vol. 70, no. 3, pp. 855-858, 2010.

[237] L. Zitvogel, L. Apetoh, F. Ghiringhelli, and G. Kroemer, "Immunological aspects of cancer chemotherapy," Nature Reviews Immunology, vol. 8, no. 1, pp. 59-73, 2008.

[238] R. Ramakrishnan, D. Assudani, S. Nagaraj et al., "Chemotherapy enhances tumor cell susceptibility to CTL-mediated killing during cancer immunotherapy in mice," The Journal of Clinical Investigation, vol. 120, no. 4, pp. 1111-1124, 2010.

[239] M. Hong, A.-L. Puaux, C. Huang et al., "Chemotherapy induces intratumoral expression of chemokines in cutaneous melanoma, favoring T-cell infiltration and tumor control," Cancer Research, vol. 71, no. 22, pp. 6997-7009, 2011.

[240] G. Tonon, "From oncogene to network addiction: the new frontier of cancer genomics and therapeutics," Future Oncology, vol. 4, no. 4, pp. 569-577, 2008.

[241] I. B. Weinstein and A. K. Joe, "Mechanisms of disease: oncogene addiction-a rationale for molecular targeting in cancer therapy," Nature Clinical Practice Oncology, vol. 3, no. 8, pp. 448-457, 2006.

[242] W. Yan, W. Zhang, and T. Jiang, "Oncogene addiction in gliomas: implications for molecular targeted therapy," Journal of Experimental and Clinical Cancer Research, vol. 30, no. 1, article no. 58, 2011.

[243] A. Boni, A. P. Cogdill, P. Dang et al., "Selective BRAFV600E inhibition enhances T-cell recognition of melanoma without affecting lymphocyte function," Cancer Research, vol. 70, no. 13, pp. 5213-5219, 2010.

[244] R. C. Koya, S. Mok, N. Otte et al., "BRAF inhibitor vemurafenib improves the antitumor activity of adoptive cell immunotherapy," Cancer Research, vol. 72, no. 16, pp. 3928-3937, 2012.

[245] S. A. Rosenberg, J. C. Yang, and N. P. Restifo, "Cancer immunotherapy: moving beyond current vaccines," Nature Medicine, vol. 10, no. 9, pp. 909-915, 2004. 


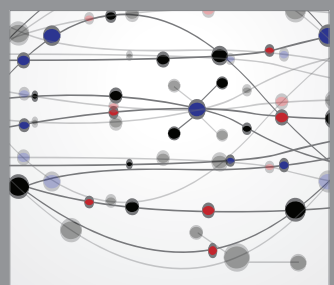

The Scientific World Journal
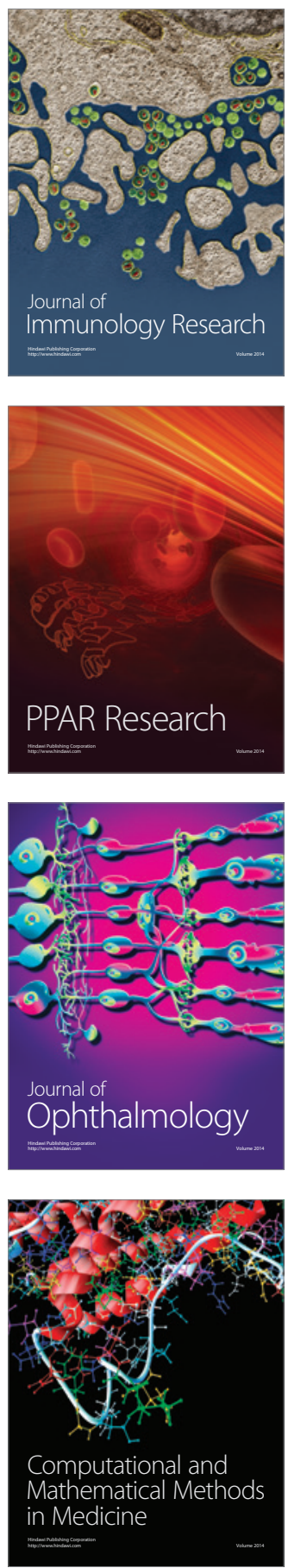

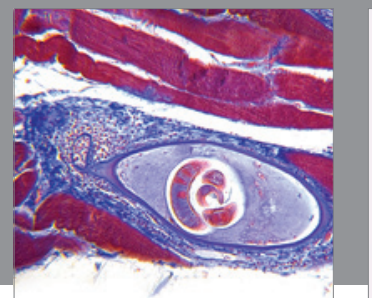

Gastroenterology

Research and Practice
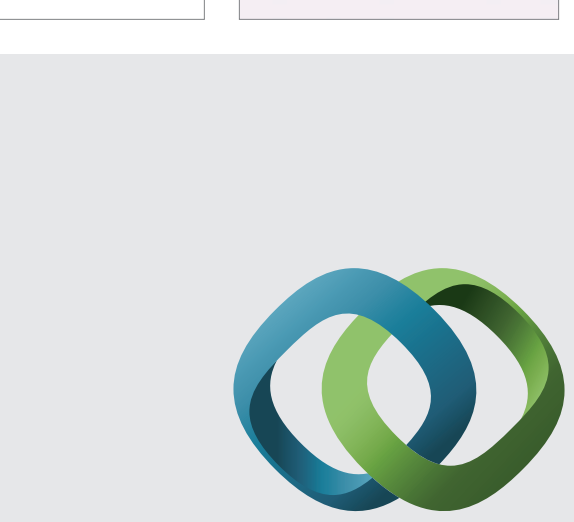

\section{Hindawi}

Submit your manuscripts at

http://www.hindawi.com
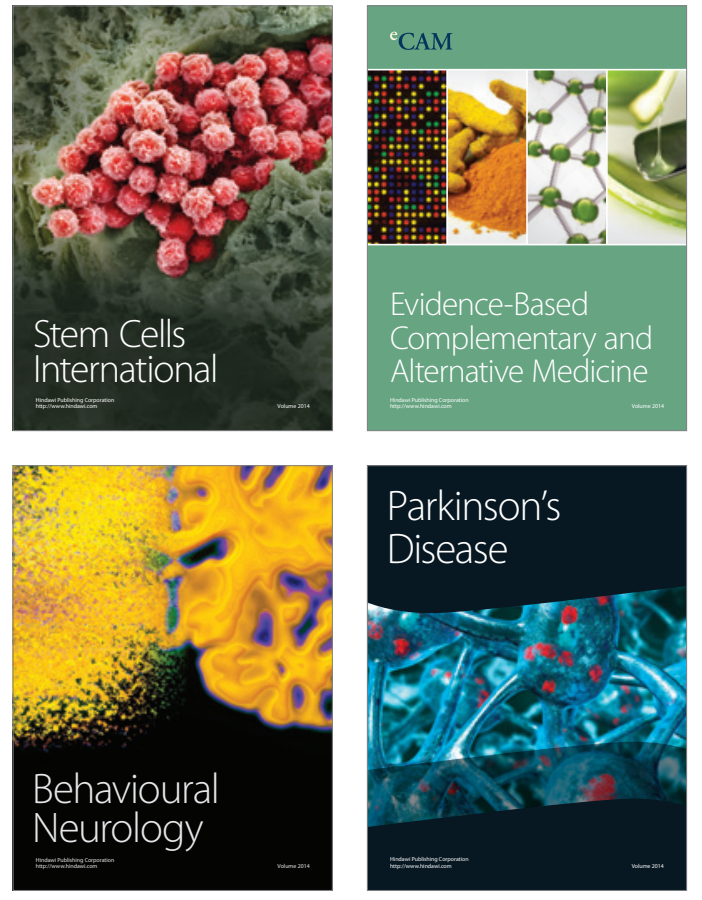
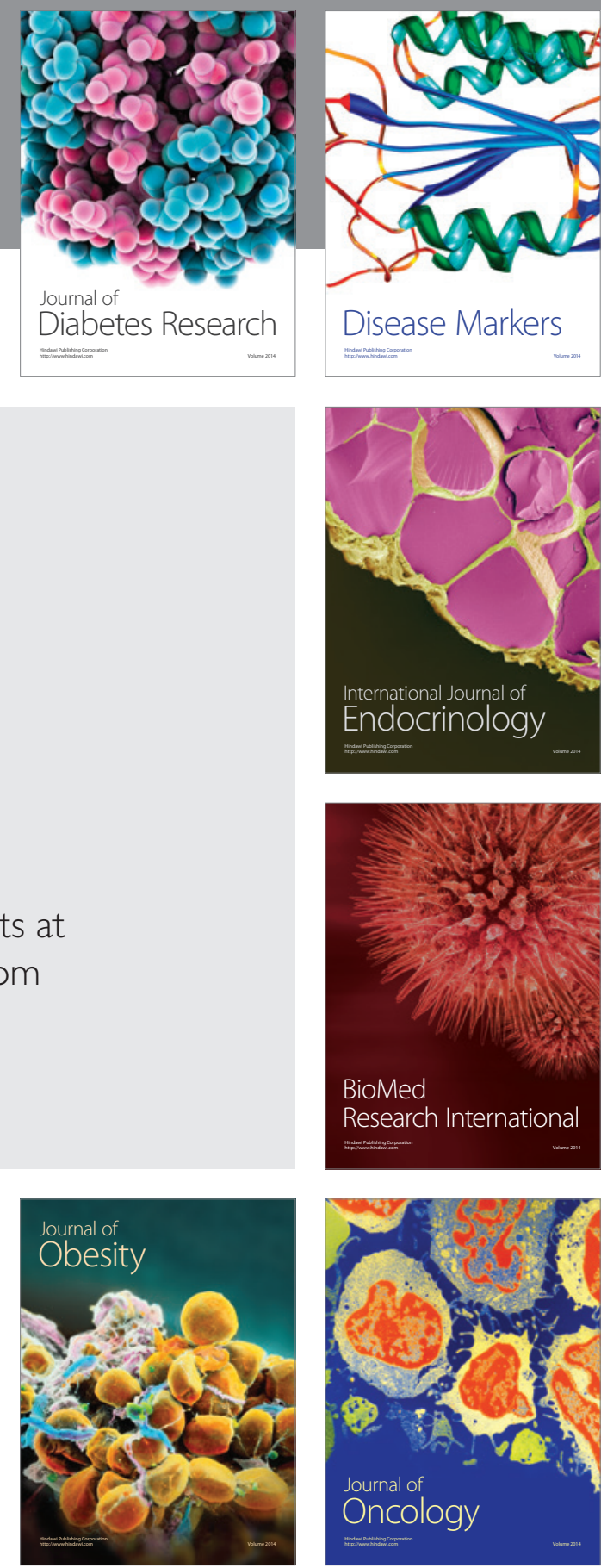

Disease Markers
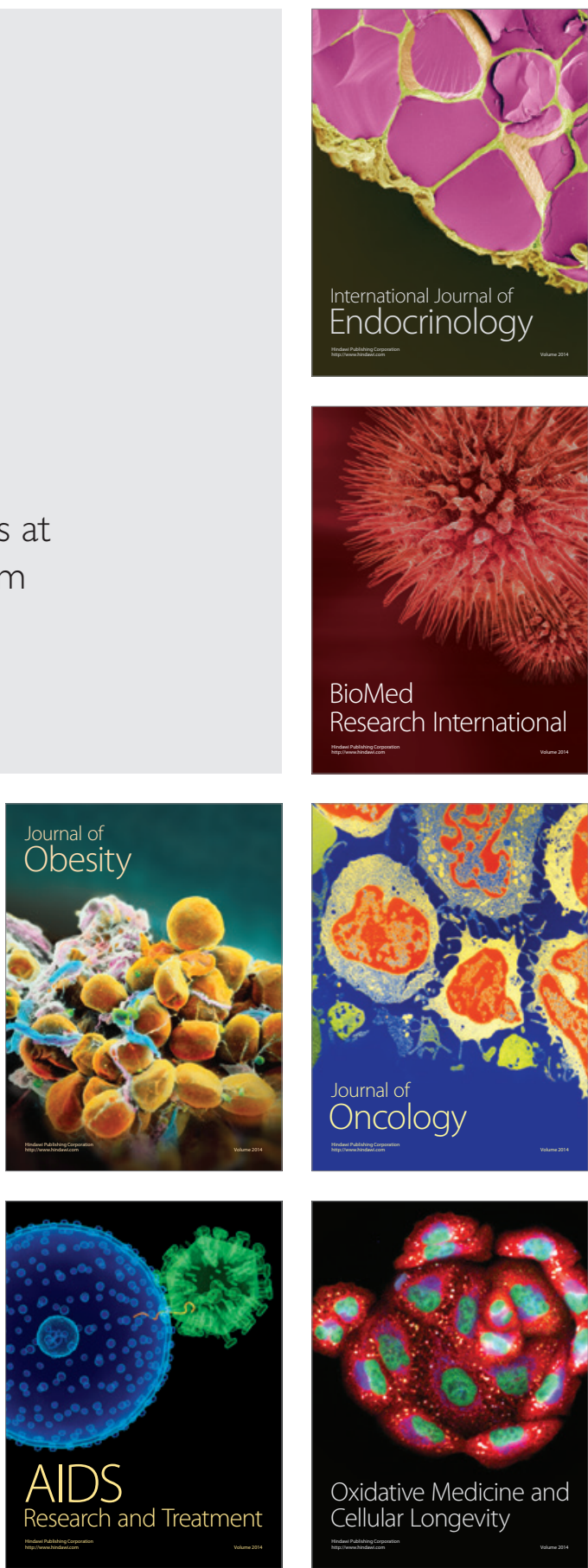